\title{
REPRESENTACIÓN DEL ESPACIO URBANO EN ALUMNOS DE PRIMARIA DE LA CIUDAD DE BAHÍA BLANCA (ARGENTINA). UN ANÁLISIS A PARTIR DE MAPAS MENTALES ${ }^{1}$
}

\author{
Carlos Andrés Pinassi \\ Departamento de Geografía y Turismo. Universidad Nacional del Sur - CONICET. andres.pinassi@uns.edu.ar \\ Miguel Seguí Llinás \\ Departamento de Ciencias de la Tierra. Universidad de las Islas Baleares. \\ msegui@uib.es
}

\section{RESUMEN}

El presente trabajo tiene como objetivo: analizar la representación mental de alumnos de educación primaria de la ciudad de Bahía Blanca, a partir de la metodología de mapas mentales; siguiendo como hipótesis que el espacio vivido de los niños de dicha aglomeración, se estructura a partir de espacios de socialización vinculados a la recreación y el esparcimiento, en detrimento de aquellos asociados a la historia y cultura del lugar. En este contexto, se obtiene como resultado, que los espacios de carácter contemporáneo prevalecen ante aquellos patrimoniales, que configuran la identidad de la sociedad local.

Palabras clave: mapas mentales, espacios recreativos, espacios patrimoniales, Bahía Blanca.

Fecha de recepción: enero 2015.

Fecha de aceptación: noviembre 2015.

1 El presente trabajo expone resultados preliminares pertenecientes a la Tesis de Doctorado en Geografía (UNS) del primer autor. La misma se realiza en el marco de la Beca Interna Doctoral, financiada por el Consejo Nacional de Investigaciones Científicas y Técnicas de la Rep. Argentina. Asimismo, forma parte del Proyecto de Grupos de Investigación: «Turismo y dinámicas territoriales: diferentes perspectivas de análisis», dirigido por la Dra. Patricia Ercolani (Dpto. de Geografía y Turismo - UNS). 


\section{ABSTRACT}

This paper aims to analyze the mental representation of primary school students in the Bahía Blanca city, starting from mental mapping methodology; following the hypothesis that the children lived space is structured for spaces of socialization associated to recreation and leisure, to the detriment of those heritage spaces. In this context, it is obtained as a result, the spaces of contemporary character prevail over those heritage, which structure the local social identity.

Keyword: mental maps, recreational spaces, heritage spaces, Bahía Blanca.

\section{INTRODUCCIÓN}

El espacio vivido se configura como un espacio subjetivo que depende de cada sujeto, de sus características personales y sociales. La espacialidad también influye en su estructuración, al igual que la historicidad como parte de una sociedad. La exploración del mismo puede realizarse a partir de la aplicación de diversas técnicas metodológicas, entre ellas: los mapas mentales, definidos como traducciones genéricas del ser y sentir de los individuos.

La ciudad como territorio dinámico, constituida por diversos componentes, materiales e inmateriales, que estructuran la trama urbana, adicionado a sus habitantes y las relaciones de poder que se dan entre los distintos actores locales, definen una cierta identidad. En este contexto, en el presente trabajo se aborda el estudio de la ciudad de Bahía Blanca, una aglomeración intermedia localizada en el Sudoeste de la provincia de Buenos Aires (Rep. Argentina).

El objetivo que guía la investigación consiste en: analizar la representación mental de alumnos de educación primaria de dicho espacio urbano a partir de la metodología de mapas mentales o cognitivos. Relacionado a ello se presenta como hipótesis, que el espacio vivido de los niños de la ciudad, se estructura a partir de espacios de socialización vinculados a la recreación y el esparcimiento, en detrimento de aquellos asociados a la historia y cultura del lugar. Diferentes investigaciones con base en el ámbito escolar (Souto, 1994; García, 2002; Morales, Caurín y Souto, 2013) y en la planificación de la ciudad (Boira, 1996, 2000 y 2008; Castro, 2005; Vara, 2008; Escudero, 2013; Naveiro, 2015) resaltan la relevancia del espacio subjetivo, en el marco de la Geografía de la Percepción, para el abordaje del espacio urbano. En este contexto Naveiro (2015: 261) destaca:

«... el análisis de la ciudad no debe ceñirse exclusivamente al análisis de su base física. Los sistemas urbanos son el soporte de multitud de usuarios permanentes o esporádicos que dan lugar a `imaginarios urbanos’, imágenes que cada uno de ellos efectúa sobre la ciudad y que representan el espacio según su percepción. Esto implica que la ciudad no sería una realidad en sí, sino la suma de múltiples realidades.»

Dicha consideración se vería enriquecida si en las políticas de gestión de estos territorios, además de los adultos, se tuvieran en cuenta los requerimientos de los niños como parte del conjunto de ciudadanos que estructuran las urbes ${ }^{2}$. El presente trabajo, pretende contribuir en este sentido.

2 En este contexto se destacan los aportes de Tonucci $(2004,2015)$. 
En primera instancia, se desarrolla el procedimiento metodológico para abordar la investigación, describiendo las variables y herramientas utilizadas para la obtención de datos de primer orden.

Posteriormente, se conceptualiza a los mapas mentales como herramienta de estudio de los espacios subjetivos, además de explorar brevemente las nociones de recreación y patrimonio cultural, constructos clave de este trabajo.

En una tercera etapa, se presenta el estudio de caso, analizando los diferentes componentes urbanos que estructuran los espacios subjetivos de los niños de Bahía Blanca.

Por último, en las reflexiones finales, se realiza un aporte a través de ciertos lineamientos propositivos en la esfera educativa y de la gestión urbana, a fin de revertir ciertos resultados obtenidos.

\section{PROCEDIMIENTO METODOLÓGICO}

Para arribar al objetivo propuesto y constatar la hipótesis planteada, se trabajó con alumnos de escuelas de educación primaria de la ciudad de Bahía Blanca. El segmento establecido se conformó por niños entre los 6 y 11 años de edad.

Con relación al criterio de segmentación geográfica, se tuvo en cuenta la división por Delegaciones que se establece a nivel distrital. Sobre un total de nueve, se abordaron seis, debido a su localización y configuración del espacio urbano bahiense. En este contexto, forman parte del área de estudio las Delegaciones: Centro, Harding Green, Las Villas, Noroeste, Norte y Villa Rosas (Fig. 1). Las restantes: Ingeniero White, General Daniel Cerri y Cabildo, constituyen localidades con un emplazamiento e impronta cultural diferencial a Bahía Blanca, por lo que no se las incluye dentro del área de estudio. Si bien guardan estrecha relación socio-espacial con la ciudad, se considera que la estructuración del espacio vivido en dichas localidades se constituye a partir de otras experiencias, relaciones sociales y espacialidad, por tal motivo el estudio se limita al centro urbano en sí mismo.

El trabajo de campo, llevado a cabo durante el segundo semestre del año 2014, se estructuró a partir de un muestreo no probabilístico o dirigido, teniendo como base la instancia de educación formal primaria de los niños. En este contexto, se identificó y seleccionó una institución educativa de gestión pública por cada una de las Delegaciones y dos de carácter privado, localizadas únicamente en el sector céntrico, dado que el emplazamiento totalitario de las mismas se da en dicha área. La selección de los establecimientos se basó en la apertura de los directivos a la aplicación de las entrevistas, sumando un total de 8 los colegios analizados (Tabla 1). Asimismo, se tuvo en cuenta la localización de las escuelas en cada una de las jurisdicciones, prevaleciendo aquellas emplazadas en las áreas centrales de cada Delegación. La aplicación del instrumento metodológico se llevó a cabo en los años de $1^{\circ}$ a $6^{\circ}$ de cada escuela, abarcado sólo un curso por cada uno de los grados. La determinación de los mismos, se dio a partir de la disponibilidad horaria de los grupos al momento de la realización de la visita, sumando en total 825 unidades muestrales (alumnos).

Con respecto a las herramientas de obtención de datos, el procedimiento metodológico se constituyó a partir de los aportes de Lynch (1959 [2008]) con la aplicación de los mapas mentales. Dicho autor, a partir del estudio de caso en tres ciudades estadounidenses (Boston, Jersey City y Los Ángeles), determina recorridos, lugares frecuentados, la «imaginabilidad» 


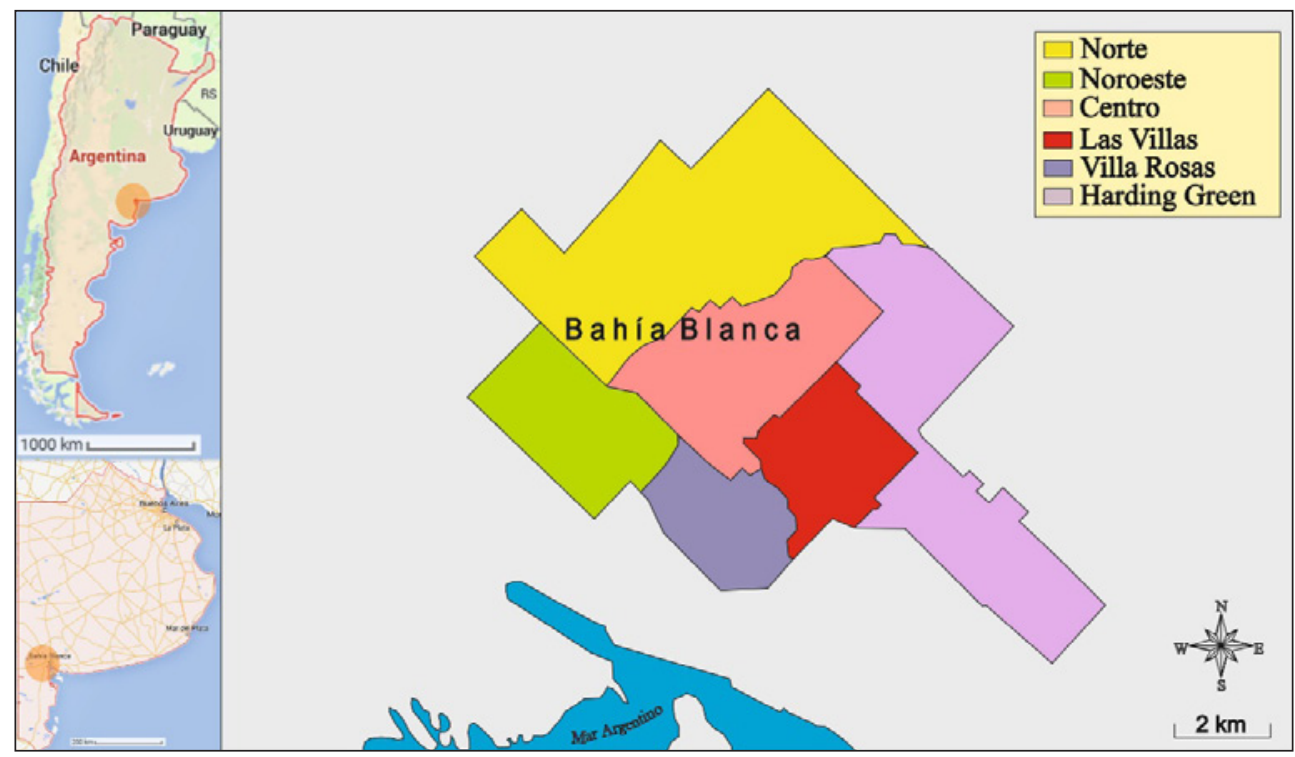

Fuente: elaboración propia en base a Municipalidad de Bahía Blanca y Google Maps (2015).

Tabla 1

INSTITUCIONES EDUCATIVAS QUE ESTRUCTURAN LA MUESTRA

\begin{tabular}{|c|c|}
\hline \multirow{2}{*}{ Delegación Municipal } & Escuelas de Educación Primaria \\
\hline \multirow{2}{*}{ Centro } & $\mathrm{N}^{\mathrm{o}} 2$ (Institución pública) \\
\cline { 2 - 2 } & $\mathrm{N}^{\mathrm{o}} 109$ (Institución privada) \\
\cline { 2 - 2 } & $\mathrm{N}^{\mathrm{o}} 3201$ (Institución privada) \\
\hline Harding Green & $\mathrm{N}^{\mathrm{o}} 33$ (Institución pública) \\
\hline Las Villas & $\mathrm{N}^{\mathrm{o}} 12$ (Institución pública) \\
\hline Noroeste & $\mathrm{N}^{\mathrm{o}} 24$ (Institución pública) \\
\hline Norte & $\mathrm{N}^{\mathrm{o}} 48$ (Institución pública) \\
\hline Villa Rosas & $\mathrm{N}^{\mathrm{o}} 23$ (Institución pública) \\
\hline TOTAL DE ALUMNOS \\
ENTREVISTADOS
\end{tabular}

Fuente: Elaboración propia en base a Dirección General de Cultura y Educación de la Pcia. de Bs. As. (2014). 
correspondiente a los elementos del espacio urbano y la identificación de ciertos componentes agrupados en cinco categorías: sendas ${ }^{3}$, nodos $^{4}$, mojones $^{5}$, bordes $^{6}$ y $_{\text {barrios }}{ }^{7}$. En este trabajo, de acuerdo al fin propuesto, sólo se limita a analizar la presencia de los componentes del espacio urbano en cada una de las representaciones mentales de los alumnos. La consigna dada consistió en: «dibujar la ciudad de Bahía Blanca», dicha premisa, amplia y no acotada al objetivo que se persigue, se sustenta en el fundamento de que la obtención de respuestas concretas buscadas, se logran a partir de una indagación general y no de forma puntual relativa a la temática investigada (Castro, 1997; Buzai, 2011). Tal connotación posibilita obtener cierta información de forma indirecta, contribuyendo a no influir en la posible respuesta de aquello que se quiere analizar.

Los mapas mentales fueron procesados a través del programa informático Dyane, Versión 2 y 4 (Santesmases Mestre, 2001 y 2009), dado que se constituye en una herramienta útil a los fines aquí propuestos.

En líneas generales, al abordar el estudio del espacio vivido, cabe precisar que si bien dichas técnicas metodológicas se aplican y miden con cierto grado de confianza, al trabajarse con un espacio subjetivo y personal, que depende de cada individuo y su relación social y con el espacio material, es imposible obtener un panorama totalitario y exhaustivo de la realidad interna de cada sujeto. En este contexto Soja (2008: 40-41) sostiene:

«En todas estas 'historias de vida' resulta imposible obtener un conocimiento perfecto o completo. Hay demasiadas cosas, desconocidas y tal vez incognoscibles, que yacen debajo de la superficie como para que sea posible contar una historia completa. Lo mejor que podemos hacer es investigar selectivamente, del modo más sutil posible, la infinita complejidad de la vida a través de sus dimensiones espaciales, sociales e históricas intrínsecas, y de su espacialidad, sociabilidad e historicidad interrelacionadas.»

Es así, que en este trabajo se aborda un aspecto particular de dicho espacio subjetivo, analizando el lugar que ocupan los espacios recreativos y patrimoniales en el «mundo interno» de los niños de la ciudad, además de otros elementos que estructuran parte del espacio geográfico local.

3 «Las sendas son los conductos que sigue el observador normalmente, ocasionalmente o potencialmente. Pueden estar representadas por calles, senderos, líneas de tránsito, canales o vías férreas» (Lynch, 2008:62).

4 «Los nodos son los puntos estratégicos de una ciudad a los que puede ingresar un observador y constituyen los focos intensivos de los que parte o a los que se encamina. Pueden ser ante todo confluencias, sitios de una ruptura en el transporte, un cruce, una convergencia de sendas, momentos de paso de una estructura a otra» (Lynch, 2008:62-63).

5 «Los mojones son otro tipo de punto de referencia, pero en este caso el observador no entra en ellos, sino que le son exteriores. Por lo común se trata de un objeto físico definido con bastante sencillez, por ejemplo, un edificio, una señal, una tienda o una montaña» (Lynch, 2008:63).

6 «Los bordes son los elementos lineales que el observador no usa o considera sendas. Son los límites entre dos fases, rupturas lineales de la continuidad, como playas, cruces de ferrocarril, bordes de desarrollo, muros» (Lynch, 2008:62).

7 Los barrios o distritos son las secciones de la ciudad cuyas dimensiones oscilan entre medianas y grandes, concebidas como de un alcance bidimensional, en el que el observador entra en su seno mentalmente y que son reconocibles como si tuvieran un carácter común que los identifica» (Lynch, 2008:62). 


\section{MAPAS MENTALES, ESPACIOS PATRIMONIALES Y RECREATIVOS COMO CONCEPTOS CLAVE}

De acuerdo a lo planteado por Lerma (2013), existen diferentes procedimientos metodológicos para explorar el espacio vivido: uno es a través de los mapas mentales, difundido desde el urbanismo por Kevin Lynch (1959) y desde la geografía por Peter Gould (1966), alcanzando en esta disciplina autores contemporáneos referenciados en este texto, como Castro y Bosque (1991), Castro (1997a, 1997b, 1999, 2004), entre otros; por otra parte, se destacan los aportes de Milgram y Jodelet (1976), quienes desde la psicología social abordaron el estudio de las representaciones sociales. A diferencia de la metodología de Lynch, estos autores basados en los aportes de Moscovici, consideran en mayor profundidad los caracteres de subjetividad en los espacios de representación, que en las variables del espacio físico o material. El método ALCESTE (Análisis Lexical de Coocurrencias de Enunciados Simples de un Texto $^{8}$ ), constituye un aporte desde los procedimientos cuantitativos. Por último, se destaca el abordaje desde la teoría de los imaginarios sociales, desarrollada por Cornelius Castoriadis ${ }^{9}$.

Según Castro y Bosque (1991), el concepto de mapa mental fue desarrollado y aplicado por Peter Gould, reconocido geógrafo ingles formado en Estados Unidos. La exploración de los mapas mentales se da en el paradigma de la Geografía Humanista en el análisis de la percepción. La generalización de resultados representativos de una determinada población, se realiza con injerencia de la Geografía Cuantitativa, que posibilita la obtención de datos numéricos comparables (Buzai, 2011). En este contexto, «la geografía de la percepción optó por una situación ecléctica entre las orientaciones positivistas y humanistas, de los primeros adoptó el uso de técnicas y procedimientos de trabajo adaptados a la psicología, pero sus temas se centraron en la representación de la información espacial, propia de los humanistas» (Pillet, 2004: 145).

Una definición genérica de mapa mental, mencionada por diferentes autores (Vivas et al., 2005; Rubio y Santarelli, 2011; Fernández, 2013) es la establecida por Milgram (1977 [2010]), quien sostiene que «un mapa mental es el dibujo que una persona lleva en su mente: las calles, barrios, plazas que son importantes para ella, de alguna forma enlazadas y con una carga emocional adjunta a cada elemento.» Puede decirse entonces, que un mapa mental se constituye de representaciones mentales del espacio geográfico, generadas involuntariamente a partir de los caracteres propios de los individuos y de su percepción, interpretación y vivencia con la realidad. Un mapa mental es la imagen traducida del espacio subjetivo individual, es la imagen reproducida del valor simbólico atribuido al medio. «El mapa le añade a la imagen, que en sí misma pertenece al mundo interior de nuestras vidas, un soplo de vida, un impulso hacia la luz interior» (Castro y Bosque, 1991: 19). Por otro lado, Escobar (1992: 50) define dichas representaciones con el concepto de «esbozo de mapas», que al igual que los mapas mentales, son definidos como «[...] croquis que los sujetos dibujan espontáneamente sobre un espacio dado.»

8 Una aplicación de esta metodología se desarrolla en Alba (2004).

9 Diferentes estudios de caso donde se aplica este enfoque pueden encontrarse en Lindón, Aguilar y Hiernaux (2006). 
Por su parte, Caneto (2000), establece una diferencia entre imagen mental y mapa mental, dado que éste se configura a partir de la imagen que se tiene del medio, por lo que su estructuración será de menor complejidad que esta última. En este contexto, el citado autor expresa que un mapa mental es:

«[...] entendido como un aspecto perceptivo de categoría inferior a la imagen, por entenderlo como un elemento formado a partir de la imagen y de connotaciones simplificadas y locativas. Esto dicho sin perjuicio de la importancia de uno u otro en el análisis espacial» (Caneto, 2000: 26).

El concepto de mapa mental ha sido puesto en cuestionamiento, aludiendo a que es conveniente denominarlo como cognitivo. Al respecto, Castro (1999) establece:

«[...] el mapa cognitivo ha tenido un mal antecedente en los mapas mentales [...]. El mapa cognitivo alude a un mapa dentro de la mente, cosa que no lo hacía el mapa mental. El mapa mental utilizaba el material consuetudinario de mapas de un país con la inclusión de regiones o provincias. Estas, las distintas regiones, se constituían en objeto de preferencia y recibían en consecuencia un mayor o menor espaldarazo de parte del público encuestado. El espaldarazo otorgado se traducía finalmente a isolíneas. El mapa de isolíneas dista mucho de ser un mapa dentro de la mente. Es decir, el mapa cognitivo alude a una interioridad mental y quiere reflejarlo de una manera fidedigna.»

Como manifiesta Alba (2010: 12) «el concepto de mapa no tiene un significado cartográfico, sino únicamente semántico»; vinculada dicha connotación a la representación o a la generación de una imagen que referencia la espacialidad de los individuos, interceptada ésta por la subjetividad de cada uno de ellos.

Por otra parte, Vivas et al. (2005: 376), sostiene que un mapa cognitivo es un «constructo que alcanza a aquellos procesos que posibilitan a la gente adquirir, codificar, almacenar, recordar y manipular la información sobre la naturaleza de su entorno.» Es decir, que posibilitan su orientación y desempeño cotidiano y determinan la vinculación con su contexto inmediato y demás individuos de la sociedad. Todas estas acciones se generan a partir de diferentes visiones de dicha realidad socio-espacial, configuradas sobre la base de ciertos sentimientos y apreciaciones específicas.

La exploración de los mapas mentales debe analizarse teniendo en cuenta que dichas representaciones son dinámicas. Los mismos constituyen una foto en un momento dado de la vida del sujeto, que variará al ir creciendo en edad, experimentando nuevas vivencias, conociendo lugares diferentes, interactuando con los demás individuos y con el medio físico que lo rodea (también cambiante).

Si bien dicho instrumento metodológico constituye una herramienta útil para abordar el espacio subjetivo, el mismo ha sido objeto de ciertas críticas. En este contexto, Boira (1998) en relación a obra de Castro (1997b), hace referencia a que el citado autor manifiesta que: 
«Para trabajar con imágenes o mapas mentales, el mejor camino no es el de la introspección -que se supone es el método que practicamos quienes nos acercamos a un sujeto para pedirle una serie de respuestas o bien su amable dibujo de la ciudad-, sino que lo es, a su juicio, el análisis de los desplazamientos y de los escenarios de conducta» (Boira, 1998: 2).

De este modo, a escala ciudad, quedan desacreditadas las diferentes técnicas introspectivas para explorar el comportamiento y percepción del espacio urbano por parte de los ciudadanos, entre ellas los mapas mentales, otorgando preponderancia en este caso a la observación de comportamientos; mientras que a escalas mayores, dichos instrumentos cobran relevancia, dado que la apreciación directa de los procederes humanos en el territorio resulta dificultosa (Boira, 1998).

Otro de los aspectos críticos a los que han sido sometidos los mapas mentales, en este caso los aportes de Lynch (1959), es la prevalencia que se le da en los mismos a los elementos físicos o materiales del espacio geográfico, quedando relegados aspectos subjetivos que no pueden ser apreciables en las representaciones (Alba, 2010). De este modo, resulta necesario complementar dicha herramienta con otras que posibiliten un conocimiento más profundo del mundo interno de los individuos. En este sentido, Reques y Boira (1992) sostienen, a partir de disímiles investigaciones, que de forma errónea el tratamiento de los mapas mentales se realiza como si los mismos fueran mapas cartográficos, siendo que ambos configuran elementos de representación espacial totalmente diferenciales, además de no considerar los aspectos inmateriales que constituyen la ciudad. Por su parte, Estébanez (2000), basa su crítica en los procedimientos de confección de los mapas, influyendo a su vez éstos en los resultados y la propia interpretación del comportamiento de los individuos. El citado autor si bien plantea ciertos cuestionamientos, reconoce la relevancia de dicho concepto, al igual que lo hace Vara (2010), determinando que si bien el mismo ha sido objeto de numerosas críticas, dada su «... dificultad de aplicación y su insuficiencia como técnica única» (Vara, 2010: 340), aún sigue siendo vigente en la actualidad, aunque se explicita a futuro una necesaria incursión en nuevas metodologías que exploren los espacios subjetivos de los individuos (Vara, 2008).

Más allá de su denominación: mental o cognitivo y de considerar sus críticas, en el presente trabajo interesa analizar su significado, interpretar su sentido, para poder entender el mundo interior y la valorización con respecto al entorno en el que nos movemos. A través de su análisis, se puede dar respuesta a los interrogantes: ¿Qué espacios se valoran en una ciudad? ¿La representación es positiva o negativa? ¿Hasta dónde se extiende simbólicamente una aglomeración? ¿Cuáles son los límites de los «lugares»? ¿Se reflejan espacios recreativos y patrimoniales? ¿Lo legitimado como patrimonio desde el punto de vista institucional, forma parte realmente del imaginario urbano?, etc.

En este contexto y a los fines de la investigación interesa plantear qué se entiende por espacios patrimoniales y recreativos. Para definir cada uno de ellos, en primera instancia, se deben considerar los conceptos base: patrimonio y recreación. El primero puede conceptualizarse desde dos esferas, una etimológica y otra más crítica. La etimológica, aparece asociada a la idea de pertenencia, propiedad y herencia de ciertos bienes, que llevándolos a un contexto colectivo y cultural, comprenden los componentes históricos que como sociedad han 
sido legados del pasado y que se trasmiten de generación en generación a partir de una preservación particular. Diversos autores conceptualizan al patrimonio cultural desde esta perspectiva (UNESCO, 1972; ICOMOS, 1999; Hernández, 2002; Crespí y Planells, 2003; Ballart y Tresserras, 2007; Camarero y Garrido, 2008; Pardo, 2008; Velasco, 2009; Querol, 2010; Mejía y Valladares, 2011; Acebo y Schlüter, 2012; Arias, 2012; Moreira y Tréllez, 2013; Torrejón, 2013). Por citar textualmente un ejemplo, Querol (2010: 11) sostiene: «El patrimonio cultural es el conjunto de bienes muebles, inmuebles e inmateriales que hemos heredado del pasado y que hemos decidido que merece la pena proteger como parte de nuestras señas de identidad social e histórica.» Por otro lado, con fuerte peso desde la antropología, se ha desarrollado una visión más crítica, considerando al patrimonio cultural (y natural) como una construcción sociocultural (Prats, 1997, 1998, 2005, 2006, 2014; Troncoso y Almirón, 2005), que ha sido creada por los individuos en sociedad, a través de un proceso complejo, en un espacio y tiempo dado, con un fin específico. Esta construcción puede variar a lo largo de la historia, determinando nuevos fines e intereses (Pinassi, 2013). De acuerdo al objetivo propuesto, interesa conceptualizar los espacios patrimoniales enmarcados en la visión etimológica, considerando que los mismos pueden definirse como espacios simbólicos, cargados de valores históricos y culturales arraigados a la sociedad local, que son representativos de la identidad comunitaria. Dichos espacios pueden encontrarse materializados a partir de componentes tangibles del patrimonio cultural, estructurarse sobre la base de expresiones del patrimonio inmaterial, o a partir de la articulación de ambos y con el resto de la ciudad. En esta integración entra en juego el concepto de patrimonio territorial, abordado en la actualidad por diversos autores (Ortega, 1998; Conti, 2010; Feria, 2010, 2013). Dicho constructo

«...toma forma desde el entendimiento del espacio geográfico como lugar, producto social singular, construcción humana elaborada a partir del sustrato físico original a través de un largo y continuo proceso histórico de transformación y evolución diferenciada y cargada de significados culturales y simbólicos que, dentro de su marco de vida habitual, son percibidos por la propia población como expresión de la memoria colectiva e interiorizados, sentidos y valorados como seña de identidad» (Florido, 2013: 179).

En este contexto, la valorización social de determinados componentes de la ciudad, se posiciona por sobre los atributos particulares de los elementos del territorio, para configurar recursos que no sólo estructuran el espacio material o físico, sí no que se posicionan en los espacios subjetivos de los residentes.

El segundo concepto clave que interesa plantear es el de recreación. El mismo puede definirse según la Real Academia Española (RAE, 2015) como: «acción y efecto de recrear» y «diversión para alivio del trabajo». En primera instancia, recrear se entiende como: «divertir, alegrar o deleitar» (RAE, 2015). La segunda connotación, considera a la actividad como liberatoria de presiones laborales, pertenecientes a un tiempo de vida obligado. Bosch (2009: 27-28), establece que la recreación

«...implica la ruptura con lo cotidiano, con la rutina, con lo que permite descubrir cosas nuevas que para el hombre significan vivencias, sentimientos e ideas que no 
experimenta habitualmente. [...] sirve para el descanso de actividades diarias de carácter obligatorias y al mismo tiempo ayuda a desprenderse de las preocupaciones que éstas originan.»

Por otra parte, Acerenza (1991: 32) manifiesta que dicha práctica recreativa considera «...cualquier tipo de uso que el hombre haga de su tiempo libre, siempre que este uso se realice con una actividad placentera». Dicho autor, a partir de la lectura que realiza de Elias y Dunning (1995), establece que las prácticas recreativas pueden clasificarse en: actividades puras o sociales, vinculadas a la asistencia a eventos de carácter formal, como también a reuniones de tipo familiar o con amigos; actividades miméticas o de juegos: éstas implican la participación activa o pasiva en diferentes deportes o actividades lúdicas; y, por último, resalta a otras actividades varias menos especializadas, como por ejemplo los paseos, que también provocan un quiebre en la rutina al igual que las anteriores destacadas (Acerenza, 2006). Entre las diferentes motivaciones psicológicas para la realización de estos tipos de prácticas resurgen el hastío, la realización de compras, los paseos, las visitas, la práctica de deportes, las razones culturales, entre otras (Boullón, 1990). En este contexto, se considera entonces a la recreación como la realización de actividades, enmarcadas dentro del tiempo libre de los individuos, que persigan la obtención de un estado placentero y que posibiliten la evasión del quehacer cotidiano (Pinassi y Ercolani, 2012). A partir de lo expuesto, puede definirse entonces a un espacio recreativo como aquellos sitios que funcionan como aglutinadores de actividades lúdicas (activas o pasivas) o de contemplación, que generen cierto placer en los sujetos y que provoquen una ruptura con las acciones ligadas al tiempo obligado de los individuos. Los espacios recreativos, se configuran en la actualidad como áreas de ocio de gran relevancia, principalmente en las grandes urbes, dado que contribuyen al desarrollo integral de los residentes. En este contexto, posibilitan el «descanso psíquico», permiten la realización de ciertas actividades que en el ámbito cotidiano no practican, amplían el «horizonte intelectual y emocional», entre otros beneficios (Iazzetta Di Stasio, 2002).

A partir del análisis de los mapas mentales de alumnos de educación primaria de la ciudad de Bahía Blanca, se analiza el peso que dichos espacios adquieren en el ser y sentir interno de los mismos, qué sitios específicos se destacan y cobran relevancia y a partir de qué componentes se estructura su espacio vivido. Dichos resultados constituyen un aporte a la planificación urbana local, considerando a los infantes como pobladores clave a la hora de gestionar el espacio urbano, teniendo en cuenta que, como expresa Tonucci (2015: 45), hasta ahora «las ciudades se han olvidado de los niños.»

\section{ANÁLISIS DEL ESTUDIO DE CASO: REPRESENTACIÓN DE LA CIUDAD DE BAHÍA BLANCA}

Bahía Blanca es una ciudad de carácter intermedio, localizada en el Sudoeste de la provincia de Buenos Aires (Argentina) (Fig. 2).

El partido de nombre homónimo, de acuerdo al último censo oficial cuenta con una población total de 301.531 habitantes (INDEC -Instituto Nacional de Estadísticas y Censos-, 2010), significando un crecimiento del 5.55\% respecto del año 2001. En el contexto nacional, representa el $0.75 \%$ de la población total del país, mientras que a escala provincial alcanza casi el $2 \%$. 
Su base económica se encuentra arraigada en la producción agropecuaria en el territorio distrital, mientras que el espacio urbano propiamente dicho funciona como centro de abastecimiento de servicios de salud, educativos, culturales, administrativos, comerciales, entre otros, a una vasta área de influencia. Asimismo, se caracteriza por una intensa actividad portuaria en Ingeniero White, a escasos kilómetros del centro bahiense, y por la presencia del polo petroquímico y sus industrias vinculantes.

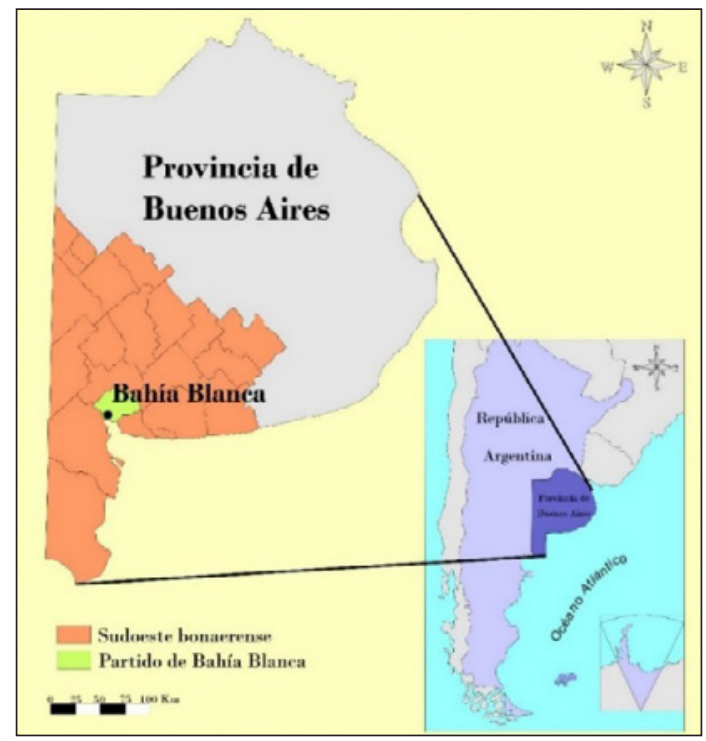

Fuente: elaboración propia en base a Luque y Álamo (2011).

Con relación al marco geográfico que caracteriza a la misma, desde el punto de vista paisajístico en la ciudad se pueden identificar diferentes áreas con cierta homogeneidad: el centro, un sector relativamente uniforme que rodea a éste último, los espacios verdes y grandes barrios residenciales, la zona portuaria e industrial (Bróndolo et al., 1994) y cabe adicionar el periurbano, de gran crecimiento en la actualidad.

El sector céntrico se caracteriza por edificios en altura que predominan en el paisaje urbano. Éstos se articulan con obras arquitectónicas de relevancia cultural e histórica dando lugar a un centro histórico no consolidado. En dicho espacio se superponen diferentes usos: administrativo, financiero, comercial, recreativo, cultural y residencial.

El área de transición entre el centro y el periurbano, se caracteriza por ser un espacio principalmente de uso residencial, con viviendas de una o dos plantas, alternadas de forma dispersa por algunos edificios en altura. Se registran concentraciones de comercios en las avenidas y calles más relevantes, como Av. Colón, Av. Alem, Brown, Vieytes, entre otras. La funcionalidad recreativa al aire libre se encuentra dada por algunas plazas y plazoletas localizadas con cierta discontinuidad en la trama urbana. 
Respecto a la tercera área, los espacios verdes y grandes barrios residenciales, la misma se localiza sobre el sector Norte y Este de la ciudad. En ellas, se pueden identificar los principales parques públicos: Parque de Mayo e Independencia, interconectados por un sistema de parques lineales en torno al cauce del Arroyo Napostá. Los barrios Palihue y Patagonia, se consolidan como grandes espacios de uso residencial, en viviendas tipo chalet, correspondientes a sectores sociales medios altos y altos. La articulación de dichas construcciones con la vegetación, otorga una mayor ponderación paisajística al sector.

La zona portuaria e industrial, se localiza hacia el Sur del ejido urbano, en la localidad de Ingeniero White, a escasos kilómetros del centro. La intensa actividad portuaria y petroquímica, coloca a la ciudad entre una de las de mayor desarrollo a nivel nacional.

Con relación al periurbano, el mismo presenta diferencias dadas por el propio paisaje, tanto natural como antropizado. El sector Norte y Este se caracteriza por ser un área de mayor altitud, determinando un paisaje diferencial y de mayor relevancia que en el área Sur y Oeste. Asimismo, el carácter de las viviendas y espacios verdes, determinan la posición socioeconómica de los pobladores de dichos sectores, concentrándose en el Norte, los espacios privados de uso residencial de mayor expansión. Hacia el Sur, los terrenos bajos, próximos al humedal, y las viviendas precarias, definen una panorámica totalmente disímil a la anterior: viviendas de chapa y de reducidas dimensiones constituyen los elementos que predominan el aspecto visible del espacio geográfico.

Como se manifestara en el apartado metodológico, para el análisis del espacio vivido de los niños comprendidos entre los 6 y 11 años de edad, se consideró una escuela de Educación Primaria Básica por cada una de las Delegaciones bajo estudio. De acuerdo a lo establecido, del total de escuelas analizadas (8), 6 se corresponden con aquellas de carácter público, mientras que 2 resultan de tipo privada. La concentración de estos últimos establecimientos se da sólo en la Delegación Centro, de este modo, se ha seleccionado a dos de las instituciones con mayor reconocimiento a escala local, a fin de poder comparar los resultados. En este contexto, casi el $50 \%$ de la muestra cursa sus estudios primarios en el área céntrica del espacio urbano, mientras que en el resto de las Delegaciones el porcentaje oscila en torno al $10 \%$. Se entrevistaron un total de 825 niños, de las cuales $61,34 \%$ corresponden a colegios públicos, mientras que el $38,66 \%$ a aquellos de carácter privado. Un poco más del $98 \%$ procedió a realizar las representaciones mentales, mientras que sólo el 1,84\% (14 alumnos) no dibujó.

Con relación al lugar de residencia, casi el $23 \%$ manifestó no conocer el nombre de su barrio. Tal resultado se debe, a que los alumnos de los años inferiores (de 6 y 7 años de edad), no sabían o recordaban en qué barrio o calle vivían. Se debe destacar, que del total de barrios con los que cuenta la ciudad (129) se han obtenido respuestas de un poco más del 90\%, siendo el Centro, Spurr y Villa Mitre, los más representativos.

De acuerdo a los tipos de representaciones, según Caneto (2000) se pueden identificar cuatro formas en la que los individuos se expresan según su espacialidad: esquemática, pictórica, fotográfica o cartográfica. En la Tabla 2 se describen cada una de ellas.

A partir del análisis de los mapas mentales se obtiene que la mayor proporción de alumnos $(96,67 \%)$ dibuja su espacio subjetivo de forma pictórica, adquiriendo gran representatividad los lugares asociados a la recreación y la escuela. Es decir, de acuerdo a lo expresado por el autor Caneto, se destaca el aspecto lúdico y los espacios de socialización. Dada la edad, el ámbito escolar configura un contexto imprescindible en el proceso no sólo de aprendizaje, 


\begin{tabular}{|c|l|}
\hline $\begin{array}{c}\text { Tipo de } \\
\text { representación }\end{array}$ & \multicolumn{1}{|c|}{ Descripción } \\
\hline Esquemática & $\begin{array}{l}\text { Tienen relación con una captación sencilla del espacio, su } \\
\text { representación se basa en la determinación de áreas, denotan un } \\
\text { conocimiento incompleto del entorno ya que se limitan a separar los } \\
\text { espacios ocupados por hechos sobresalientes para el individuo. }\end{array}$ \\
\hline Pictórica & $\begin{array}{l}\text { La representación es muy gráfica y carece de referencias, relaciona } \\
\text { parte del espacio con sus intereses, sobre todo resalta el aspecto } \\
\text { lúdico o social. }\end{array}$ \\
\hline Fotográfica & $\begin{array}{l}\text { Sobresale el detalle y la figura perceptiva, destaca los aspectos } \\
\text { relevantes por lo general con colores, que en definitiva establecen } \\
\text { una jerarquización espacial. }\end{array}$ \\
\hline Cartográfica & $\begin{array}{l}\text { La proporción y la correcta representación de la vista en planta, } \\
\text { denotan una observación particular y multidimensional del entorno. }\end{array}$ \\
\hline
\end{tabular}

Fuente: Caneto (2000).

sino también de crecimiento e intercambio comunitario. La forma esquemática de representación adquiere el 2,59\%, la cartográfica el 2,47\% y, por último, la fotográfica el 1,23\%.

Respecto de la escala geográfica, la mayor proporción de la muestra dibujó a escala ciudad $(56,2 \%)$ o ciertos sitios de ella que exceden la escala barrial, obteniendo esta última el $38,1 \%$. Aquellas de tipo regional, nacional y otra no alcanzaron valores representativos, en comparación con las dos primeras mencionadas (Fig. 3). Cabe destacar, que los mapas mentales que manifiestan la estructura de la ciudad, o al menos sitios que exceden el ámbito barrial, cobran mayor relevancia en las instituciones educativas del centro del espacio urbano, dado que gran parte de los alumnos se desplazan hacia el colegio desde diversos puntos de Bahía Blanca. La representatividad resulta mayor en el caso de las escuelas privadas. Por otro lado, la escala barrial adquiere cierta relevancia en aquellos establecimientos que se emplazan fuera de la Delegación Centro, siendo Villa Harding Green y Noroeste los de mayor notoriedad.

En relación a los elementos identificados de la trama urbana, en primera instancia se los agrupó de acuerdo a las categorías definidas por Lynch (1959), para posteriormente realizar un análisis más profundo de aquellos sitios o lugares que se reflejan de manera reiterada. El citado autor destaca 5 elementos: sendas, bordes, barrios, nodos e hitos o mojones. Para el caso analizado, los espacios subjetivos de los niños se estructuraron a partir de nodos $(88,9 \%)$, es decir diferentes espacios de encuentro (principalmente de uso recreativo) (Fig. 4); seguido por hitos con el 29,3\%, constituidos en este caso por ciertos edificios en altura, otros de carácter histórico, como el Teatro Municipal, la Universidad Nacional del Sur, o la Plaza Rivadavia (conformada ésta además como nodo dada la posibilidad de ingreso) con el Monumento a Bernardino a Rivadavia en su centro. Las sendas ocupan el tercer lugar $(17,9 \%)$. En este caso, una de las vías más representativas es Avenida Alem. Esto puede asociarse al carácter vinculante al ocio de dicho espacio, dado que funciona como concentrador 
de restaurantes y confiterías, a la vez que posibilita el acceso al Parque de Mayo. Asimismo, cobran relevancia las calles que se encuentran en torno al área céntrica, principalmente las que delimitan la Plaza Rivadavia. Lo mismo sucede con la Plaza Bartolomé Mitre (Villa Mitre), que en gran parte de los mapas cognitivos se representa el sector, inclusive con los nombres de las calles. En el caso de los barrios, dado que la mayor parte de los dibujos realizados adquiere la forma pictórica, no se determinan patrones comunes que posibiliten asignar la presencia de dichos elementos. Si bien se expresa un sector particular de la ciudad con caracteres diferenciales al resto de la trama urbana, la mayoría de las representaciones carecen de tales atributos por lo que resulta dificultosa la diferenciación de los mismos. Por el contrario, ha resultado de fácil reconocimiento en la tipología esquemática o cartográfica de la ciudad. Cabe destacar, que en la Delegación Noroeste, a diferencia del resto, el porcentaje del elemento barrio adquiere cierta representatividad. Por último, los bordes se posicionan en el quinto lugar. Aquí se destaca la presencia de «la ría», como comúnmente se nombra

Figura 3

ESCALA REPRESENTADA (\%)

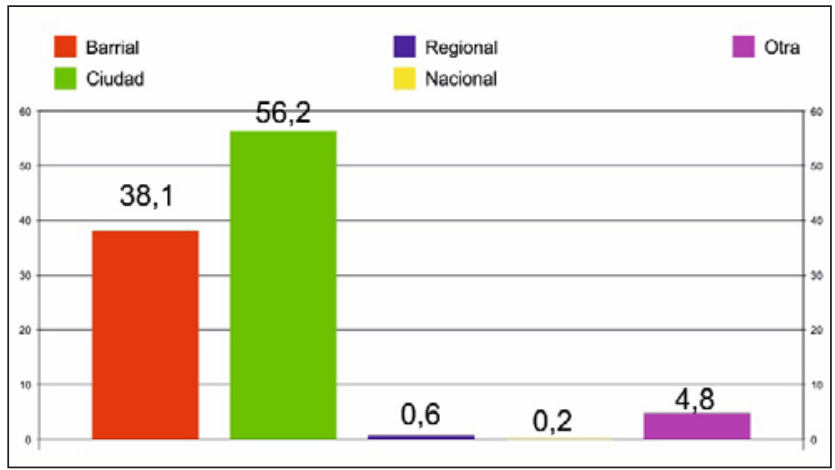

Fuente: elaboración propia (2015).

Figura 4

ELEMENTOS REPRESENTADOS EN LOS MAPAS (\%)

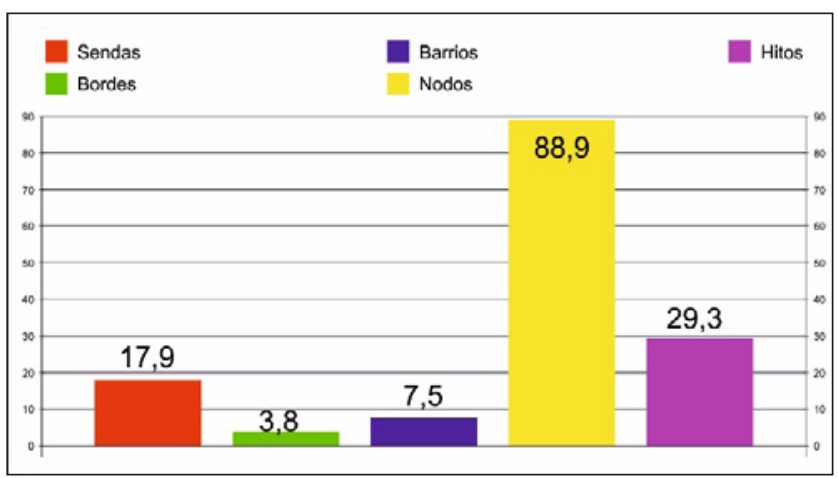

Fuente: elaboración propia (2015). 
al estuario de Bahía Blanca, como el componente más representativo. Cabe resaltar que las representaciones mentales dibujadas por los alumnos se estructuran a partir de la integración y articulación de diferentes elementos, es así que un mapa cognitivo puede constituirse a partir de nodos, hitos, sendas, etc. Tal apreciación se traduce en los valores porcentuales de la Figura 4, dado que la sumatoria excede el $100 \%$. Dicha característica se reitera en varias de las figuras que integran el presente trabajo de investigación, dada la convivencia de disímiles componentes en un mismo dibujo.

Teniendo como parámetro de análisis los elementos genéricos del espacio urbano que se representan en los mapas mentales, más de la mitad de la muestra dibujó sitios de carácter recreativo $(51,5 \%)$, en los que adquirieron relevancia los juegos infantiles $(24,9 \%)$. En este caso, la referencia a espacios de socialización e intercambio durante el tiempo libre de los niños es de gran notoriedad. Dichos valores demuestran que más del 75\% de los entrevistados dibujaron algún lugar o elemento asociado a la recreación y el esparcimiento (Fig. 5). Si bien en ciertas ocasiones, sólo se dibujó por ejemplo algún juego infantil (hamacas, toboganes, etc.), sin hacer referencia a ciertos espacios de ocio en particular, se debe resaltar la preponderancia del atributo lúdico en el segmento analizado. Tal connotación debe contextualizarse en forma directa con la edad del grupo con el que se trabaja. Cabe destacar, que los valores obtenidos se calcularon relacionando las frecuencias de respuesta y el total de unidades muestrales. Es así que en algunos mapas mentales aparecen reflejados diferentes elementos del espacio urbano, dando como resultado los porcentajes obtenidos.

Un dato interesante es el lugar que ocupan las vías de circulación (calles/avenidas) en las representaciones. Las mismas se posicionan en el tercer lugar con el 19,6\%. En este caso, como se destacara, las principales mencionadas fueron aquellas en torno al sector céntrico, cómo también las que circunscriben la plaza de Villa Mitre.

Los edificios en altura también caracterizan a los mapas cognitivos (17,5\%). En este caso, la proliferación de dichas estructuras contemporáneas generalmente se reflejan en torno a la Plaza Rivadavia. En algunos casos, aparecen articulados con espacios comerciales.

En quinto lugar, cobran relevancia los edificios de carácter histórico con el 14,8\%. Si se considera a esta categoría asociada a la de monumentos, que alcanza el 6,9\%, puede afirmarse que los componentes asociados al patrimonio cultural alcanzan un valor representativo.

Las escuelas, comercios, viviendas bajas o casas y los automóviles, completan los demás componentes que se posicionan con valores superiores al 10\%; el resto de los elementos no superan dicha cifra. Se debe mencionar, que previo al análisis y determinación de categorías genéricas de aquellos elementos (estructurales y dinámicos) que constituyen el espacio urbano, se asignaron como posibles: las industrias, cursos de agua (arroyos) y las vías del ferrocarril como componentes relevantes de la trama. En este contexto, dichas variables no obtuvieron representación alguna, dando como resultado la nula consideración en los mapas cognitivos.

Con relación a los tipos de espacios específicos representados, se estableció una clasificación en tres categorías: espacios recreativos, espacios patrimoniales y espacios de consumo. En los espacios recreativos, se incluyen aquellos sitios públicos o privados, abiertos o cerrados, destinados a la recreación y esparcimiento durante el tiempo libre de los niños; en los espacios patrimoniales, se consideran aquellos espacios materiales o manifestaciones del patrimonio cultural inmaterial que forman parte del acervo histórico de la ciudad; por 
último, los espacios de consumo, contemplan aquellos lugares caracterizados por un uso comercial, en los que se produce la venta de bienes y servicios. Si bien se tiene en cuenta que los espacios recreativos y patrimoniales pueden configurarse en aquellos de consumo, se ha establecido tal distinción a los fines de la investigación.

En este contexto, los espacios recreativos adquieren una representatividad del 53\%, seguidos por los patrimoniales (20\%), los de consumo, con el 14\%, y otros espacios o componentes, con el $13 \%$ (Fig. 6).

Dentro de los espacios recreativos, las mayores proporciones corresponden a espacios verdes de carácter público (Fig. 7). En primer lugar, se posicionan las plazas barriales como principales sitios destinados a la recreación. Por mencionar algunas de las más representati-

Figura 5

ELEMENTOS GENÉRICOS DEL ESPACIO URBANO REPRESENTADOS (\%)

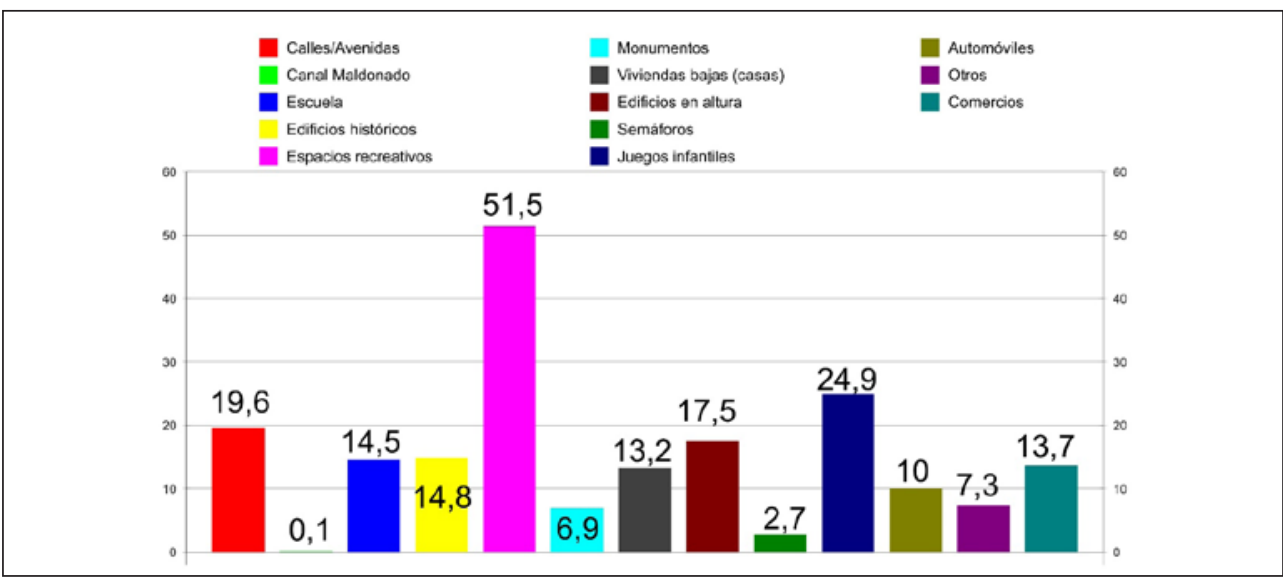

Fuente: elaboración propia (2015).

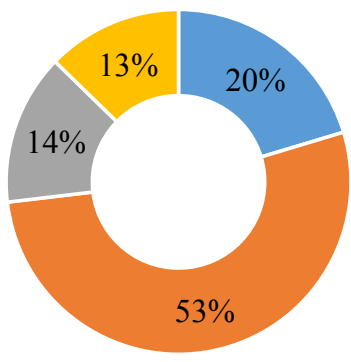

- Espacios patrimoniales

- Espacios recreativos

Espacios de consumo

Otros

Fuente: elaboración propia (2015). 
vas, que no sólo se dibujan, sino también que se escribe su nombre en el mapa mental, son: la Plaza Vista Alegre, localizada en el Noroeste de la ciudad en el barrio homónimo; y la Plaza Bartolomé Mitre en Villa Mitre. En segundo lugar, aparece la Plaza Bernardino Rivadavia (Fig. 8). La misma se representa de manera reiterada de dos maneras particulares: una, de forma pictórica con los juegos infantiles y, otra, vista en planta con los caminos internos y en su centro el monumento a Rivadavia. Cabe destacar de estos dos primeros espacios, que al relacionarlos con la escala dibujada, las plazas barriales se posicionan como los primeros sitios plasmados en la escala barrial; mientras que en la escala ciudad, la Plaza Rivadavia, adquiere mayor notoriedad que las anteriores.

En tercer lugar, los residentes dibujan otros espacios de uso durante el tiempo libre, esta categoría que alcanza el 14,3\% se conforma por canchas de fútbol barriales, polideportivos, como en el caso del Barrio Coronel Estomba, el circo, bibliotecas barriales, entre otros. Es decir, que se agrupan una serie de componentes que por sí solos no adquieren gran representatividad.

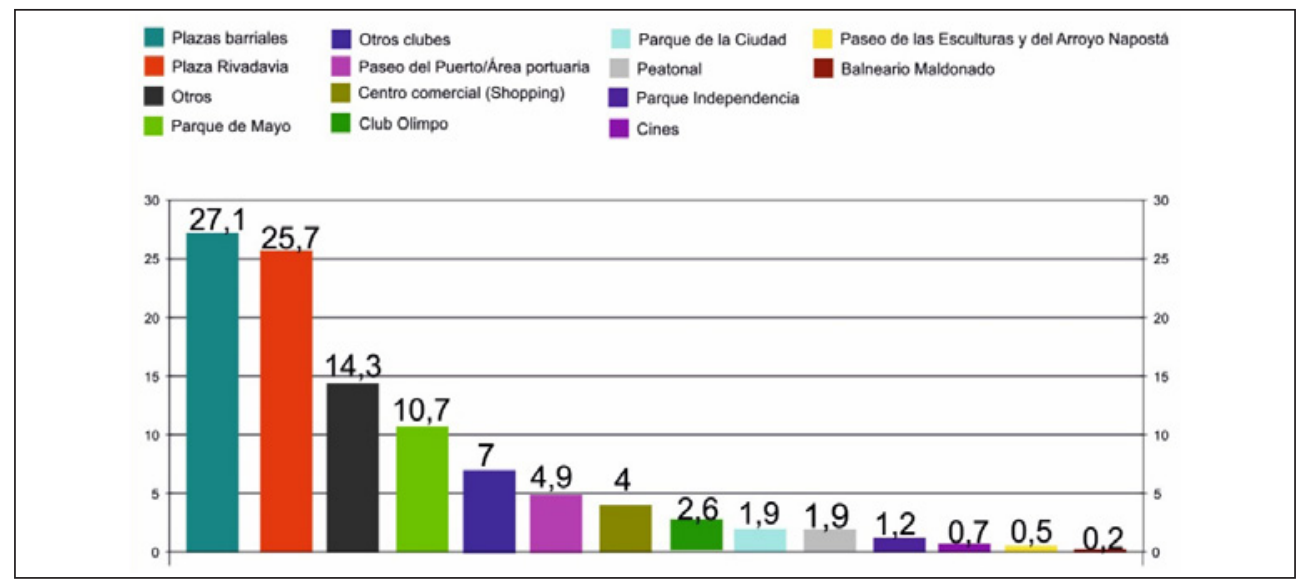

Fuente: elaboración propia (2015).

El Parque de Mayo, se posiciona en el cuarto lugar. El mismo se plasma en los dibujos de manera reiterada asociado a su arco de ingreso, que forma parte del patrimonio urbano local (Fig. 9). El sector de juegos y la pista de bicicletas también cobran relevancia.

Los clubes deportivos se configuran como espacios de gran representatividad, no sólo abocados a la práctica de fútbol, sino también: básquet, patín, natación, entre otras disciplinas. En este caso, se procedió a dividir a los mismos en dos categorías: una, que contempla solamente al Club Olimpo, dada la notoriedad del mismo por formar parte de la Primera División de fútbol de Argentina, por su antigüedad y cantidad de afiliados; y una segunda, que enmarca a otros clubes, entre los que se destacan: Napostá, Villa Harding Green, Universitario, Bella Vista, Liniers, Sportiva, Villa Mitre, etc. Entre ambos grupos alcanzan un 9,2\% de representatividad sobre el total muestral. 
Figura 8

REPRESENTACIONES DE LA PLAZA B. RIVADAVIA

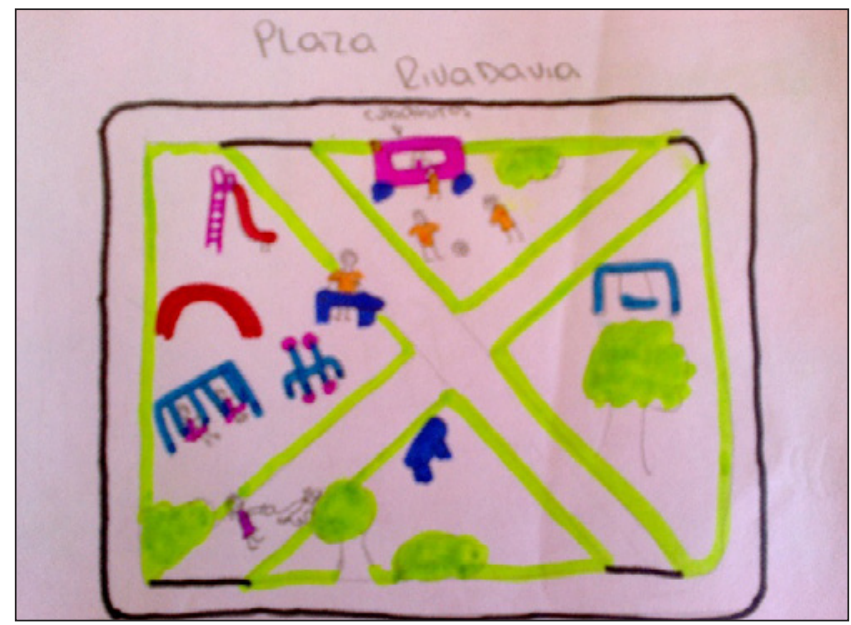

Fuente: elaborado por Tiziana (11 años).

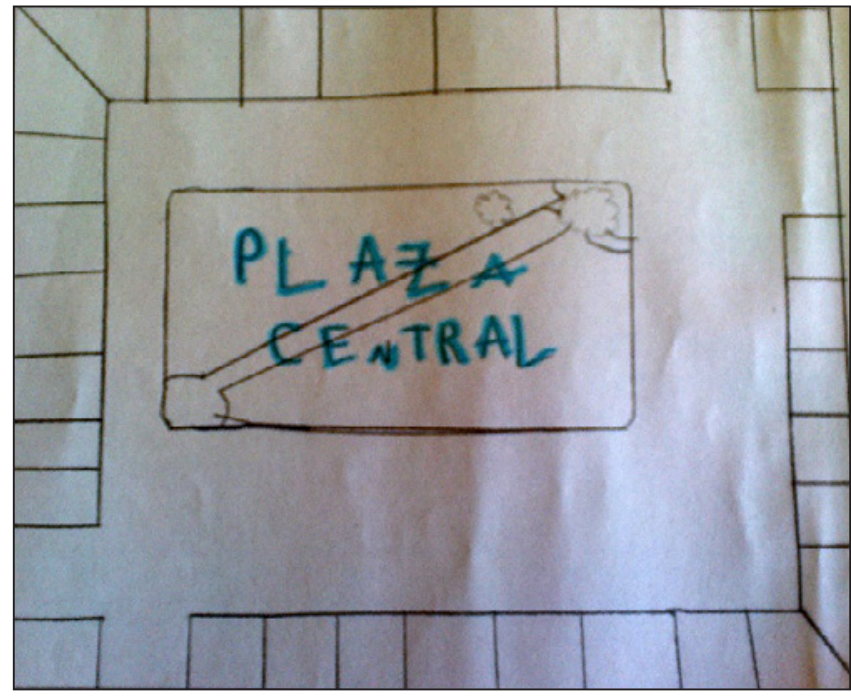

Fuente: Elaborado por Agustín (11 años).

El sexto lugar lo ocupa el sector costero. Si bien dicho espacio se emplaza en Ingeniero White, la proximidad al centro y continuidad urbana conlleva a que a veces se confunda dicho territorio como un barrio de Bahía Blanca. Si bien la disponibilidad de terreno abocado al uso recreativo es escasa, el paisaje característico del estuario con las barcazas de pesca artesanal, en contraste con los grandes barcos y galpones de acopio, constituyen las principales representaciones en los dibujos. 


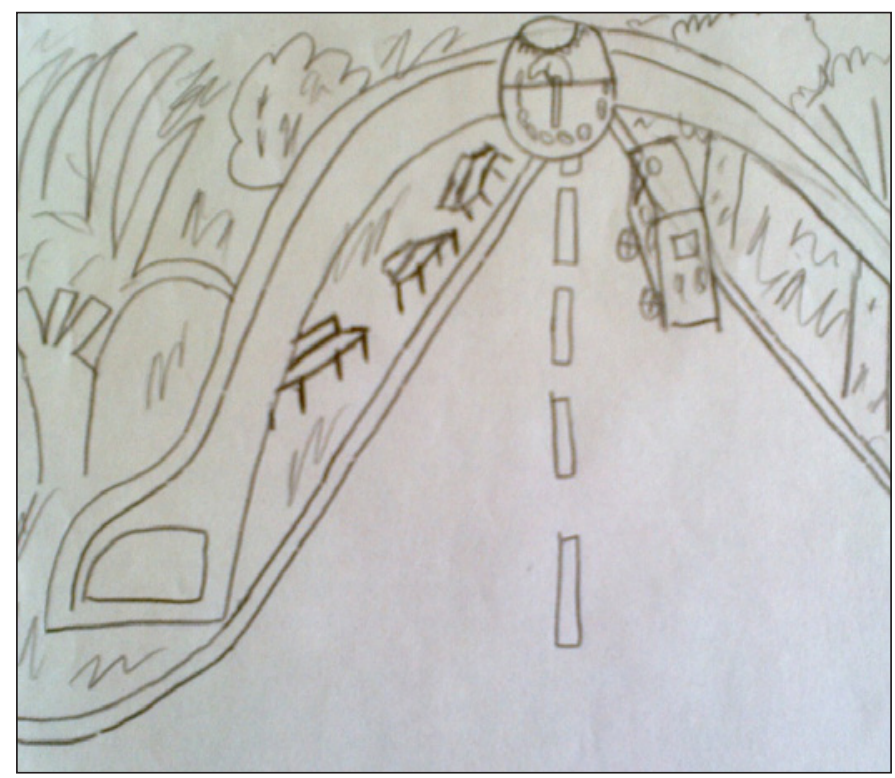

Fuente: elaborado por Alejo (11 años).

El centro comercial «Bahía Blanca Plaza Shopping», alcanza el 4\% de las imágenes. En este caso, dicho sitio se configura tanto como espacio de ocio como de consumo. El mismo siempre se manifiesta en los dibujos visto desde su exterior. Tal connotación puede reflejarse por la monumentalidad del edificio y su emplazamiento, cercano a una avenida de gran circulación como lo es Avenida Cabrera. Si se analiza dicho sitio con relación al carácter de las instituciones educativas, se observa que en aquellas privadas, los porcentajes de representación de dicho paseo de compras, resultan mayores a los obtenidos en los colegios públicos. En este contexto, los primeros alcanzan un porcentaje promedio de representación muestral de 7,25\%, mientras que los segundos no llegan al 1,5\%. Estas variaciones según la categoría de establecimiento educativo y por ende el ingreso de las familias, pueden sustentarse a partir de lo identificado a nivel general en la Encuesta Nacional de Gastos de los Hogares (INDEC, 2010), que permite caracterizar las condiciones de vida de los hogares en términos de acceso a bienes y servicios. Al descender en la escala de ingresos, son menores las proporciones del presupuesto familiar que se destinan a prácticas turísticas y recreativas, debido a que existen necesidades más urgentes que satisfacer (Schenkel, 2013). Si bien la citada autora hace referencia al turismo como actividad de consumo, sólo se resaltan aquí determinadas actividades de esparcimiento y recreación que dado su carácter, tienen asociado un perfil específico de usuarios.

El resto de los espacios de ocio: Parque Independencia, Paseo de las Esculturas y del Arroyo Napostá, Parque de la Ciudad, entre otros, no alcanzan valores superiores al $2 \%$ por lo que su representatividad no resulta trascendente. 
En el marco de los espacios patrimoniales, en casi el 80\% de los mapas no se registraron sitios ni componentes asociados al patrimonio cultural bahiense. Tal ponderación muestra la gran diferencia que existe con los espacios recreativos, que superaron más del $50 \%$.

Analizando dichos valores según las instituciones educativas (Fig. 10), se observa que los mayores porcentajes de inclusión de los bienes culturales se dan en las escuelas privadas. Se supera en ambos casos el $20 \%$. Puede atribuirse ello a la realización de paseos por la ciudad y al consumo de espectáculos culturales que se da en el ámbito escolar, según manifestaron los directivos. El colegio $\mathrm{N}^{\circ} 48$, de carácter público, correspondiente a la Delegación Norte, constituye una excepción al patrón, dado que los niveles de representación resultan ser superiores al resto de las instituciones, inclusive las escuelas privadas. Tal connotación se produce a partir de la contemplación de ciertos bienes patrimoniales con los que cuenta el sector. En el barrio se emplaza un edificio de grandes dimensiones en el que antiguamente funcionaba un matadero municipal. Luego de varias tentativas, a partir de su inclusión en el inventario de patrimonio arquitectónico local, se lo refuncionaliza dando origen a un gran polideportivo de uso comunitario y a la sede de la Delegación Norte (Fig. 11). En este contexto, el uso activo del patrimonio que realizan los niños, da cuenta de los resultados obtenidos. Para los casos de las instituciones de Villa Harding Green, Las Villas y Villa Rosas, si bien en comparación al resto los porcentajes no superan el $20 \%$, se mantienen en una media en torno al $17 \%$. En el otro extremo, se encuentran las escuelas $\mathrm{N}^{\circ} 2$ y $\mathrm{N}^{\circ} 24$, pertenecientes a las delegaciones Centro y Noroeste, respectivamente. En este caso, ambas instituciones se caracterizan por poseer una matrícula de alumnos que pertenecen a barrios de condición socioeconómica media-baja y baja. Tal connotación, sin ser nexo causal directo de los resultados obtenidos, influye en gran medida, dada la escasa disponibilidad de recursos de las familias, en el acceso al consumo cultural y recreativo en este tipo de sitios, como a la información o instrucción a nivel general.

Figura 10

REPRESENTACIÓN PATRIMONIAL SEGÚN INSTITUCIÓN EDUCATIVA (\%)

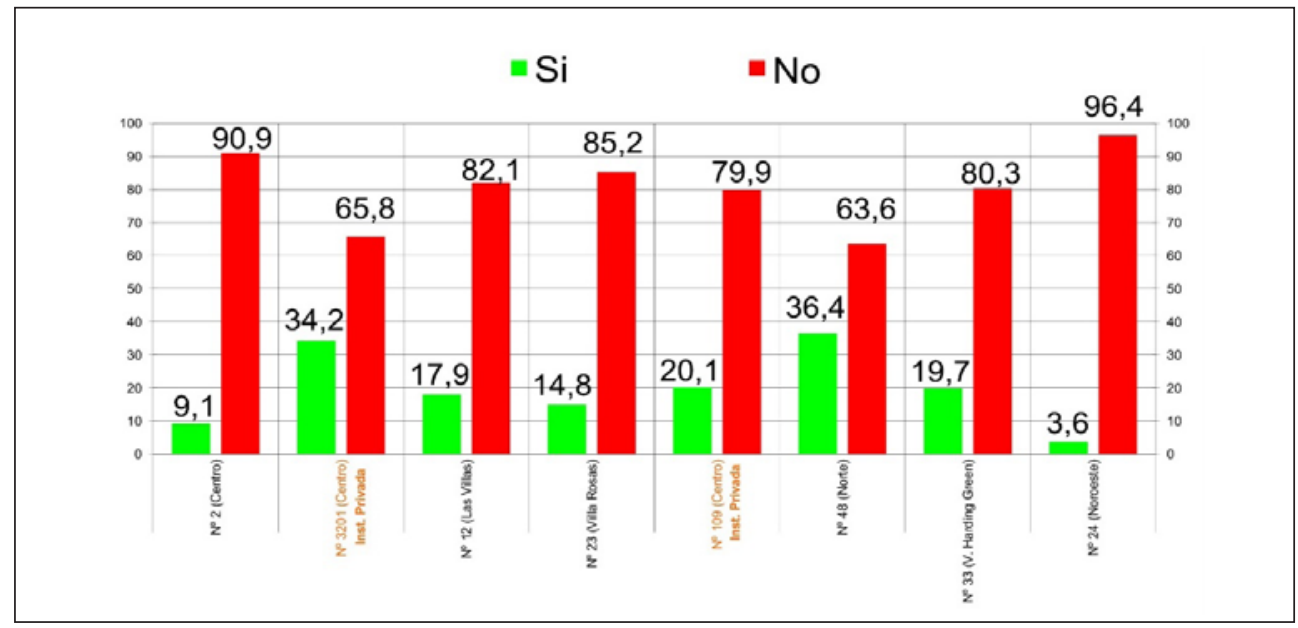

Fuente: elaboración propia (2015). 


\section{Figura 11}

REPRESENTACIONES DEL POLIDEPORTIVO DEL BARRIO CNEL. ESTOMBA

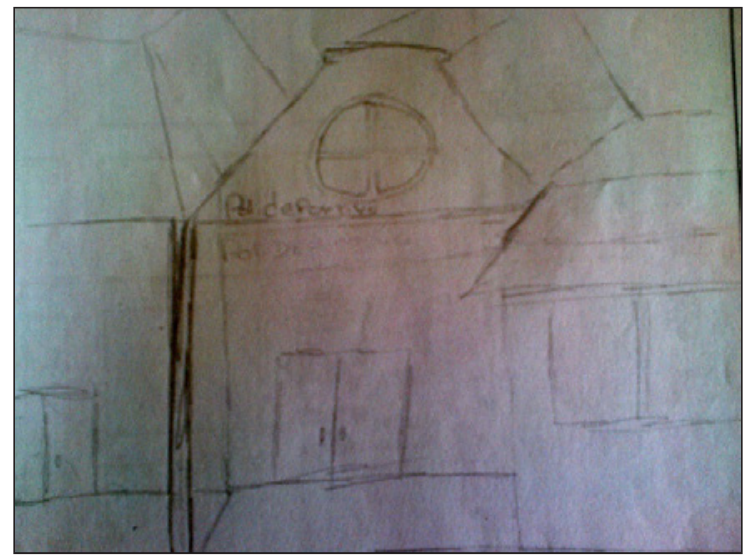

Fuente: elaborado por Juana (12 años).

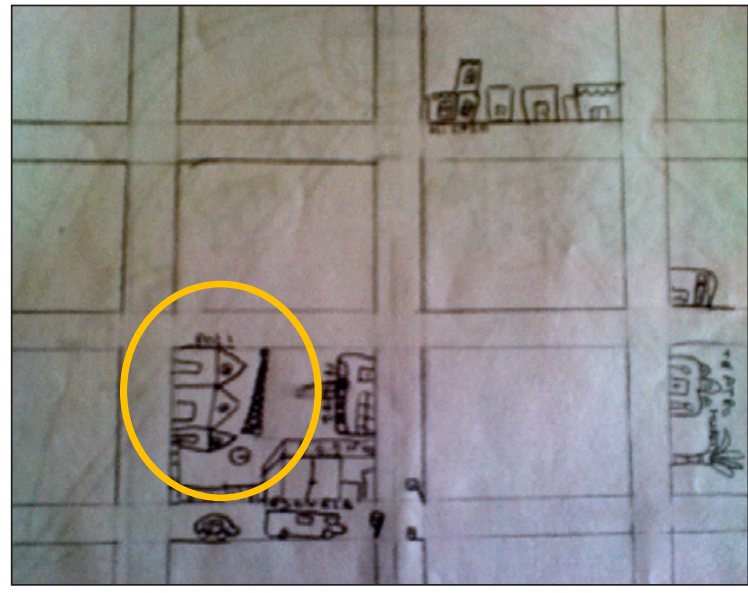

Fuente: elaborado por Anahí (11 años).

Entre los espacios patrimoniales que mayor representación tienen (Fig. 12), en primera instancia se destaca la categoría: otros componentes, es decir de aquellos que por sí mismos no alcanzan gran valorización. En este caso, el 21,8\% se conforma por ciertos monumentos de relevancia a escala barrial, como el localizado en la Plaza Bartolomé Mitre, o el dedicado a los Ex Combatientes de Malvinas en el Paseo de la Mujer, el portal de ingreso al barrio en la Delegación Noroeste, el edificio del Hospital Municipal, el polideportivo del barrio Cnel. Estomba, algunas capillas o iglesias relevantes a nivel barrial, ciertas de las esculturas del paseo homónimo, entre otros.

En segundo lugar se posiciona el portal de ingreso al Parque de Mayo (17,6\%). Este componente forma parte del área patrimonial de Avenida Alem, con declaratoria a nivel 
Figura 12

ESPACIOS PATRIMONIALES REPRESENTADOS (\%)

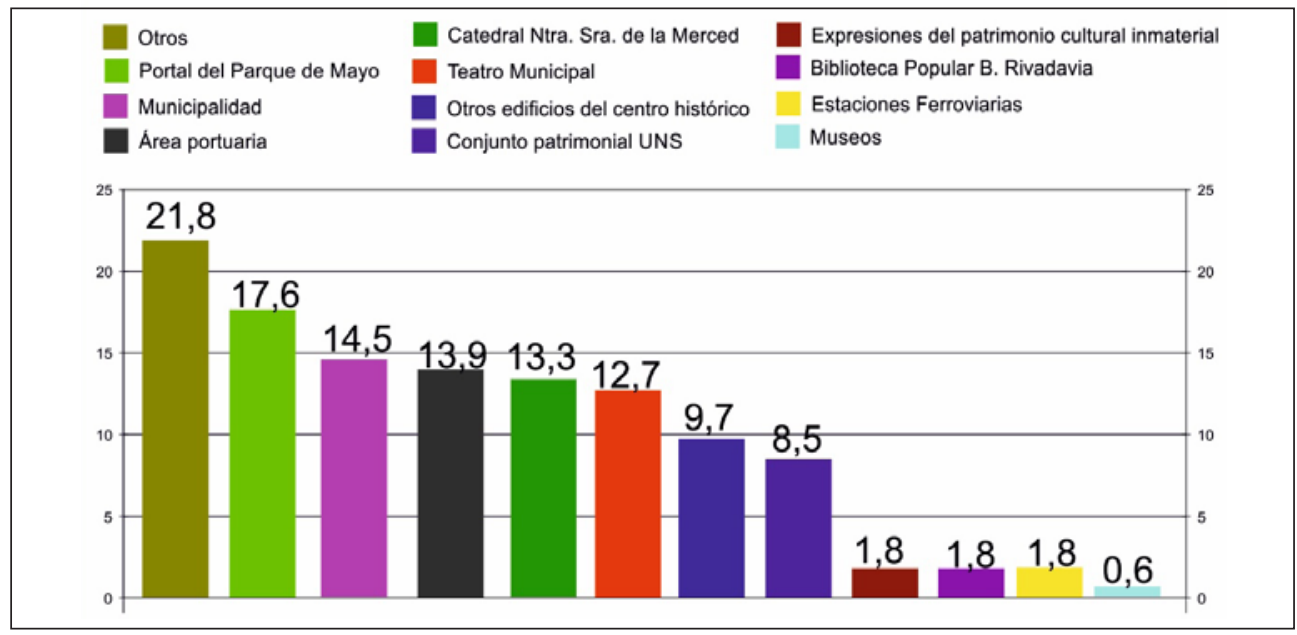

Fuente: elaboración propia (2015).

municipal. Cabe destacar, que en los mapas mentales este recurso cultural aparece en algunas ocasiones asociado al espacio verde, mientras que en otras, solamente se lo dibuja como único elemento representativo de la ciudad.

El Palacio Municipal alcanza el 14,5\%. Su emplazamiento estratégico dentro del centro histórico y urbano de la ciudad, asociado a su simbolismo y monumentalidad, determinan que su posicionamiento dentro de los espacios subjetivos de los niños sea notorio.

El área portuaria como espacio patrimonial y de recreación, cobra también relevancia en las representaciones mentales $(13,9 \%)$. La presencia del Paseo del Puerto es una de las principales causas de la inclusión en los dibujos. Si bien el mismo es reducido, se conforma como uno de los escasos sectores accesibles para obtener una vista del estuario, diferencial al paisaje urbano en el que viven los residentes bahienses.

Con un valor próximo al anterior $(13,3 \%)$, se posiciona el mayor templo religioso de la ciudad, la Catedral Nuestra Señora de la Merced, edificio que rinde culto a la patrona de Bahía Blanca. Cabe aclarar que en la mayoría de los dibujos dicho edificio aparece en el contexto del centro urbano y casi nunca se lo manifiesta solo como el único elemento patrimonial representativo (Fig. 13), como sucede por ejemplo con el Palacio Municipal, el portal de ingreso del Parque de Mayo o el Teatro Municipal. Este último, localizado en el extremo Sur de la Avenida Alem, se posiciona en el sexto lugar. Su ubicación como estructura única en la cuadrícula, rodeada por las plazoletas Payró y Dorrego jerarquizan su valor paisajístico. Asimismo, dicho espacio cultural, funciona como punto de encuentro de festejos y manifestaciones de los ciudadanos (Fig. 14).

Los edificios patrimoniales del centro histórico, además de los ya mencionados, también adquieren importancia, es así que alcanzan en conjunto el 9,7\%. Entre ellos se destacan obras de gran valor patrimonial, pero dada su función no logran protagonismo en los espacios vivi- 
Figura 13

REPRESENTACIÓN DE LA CATEDRAL NTRA. SRA. DE LAMERCED

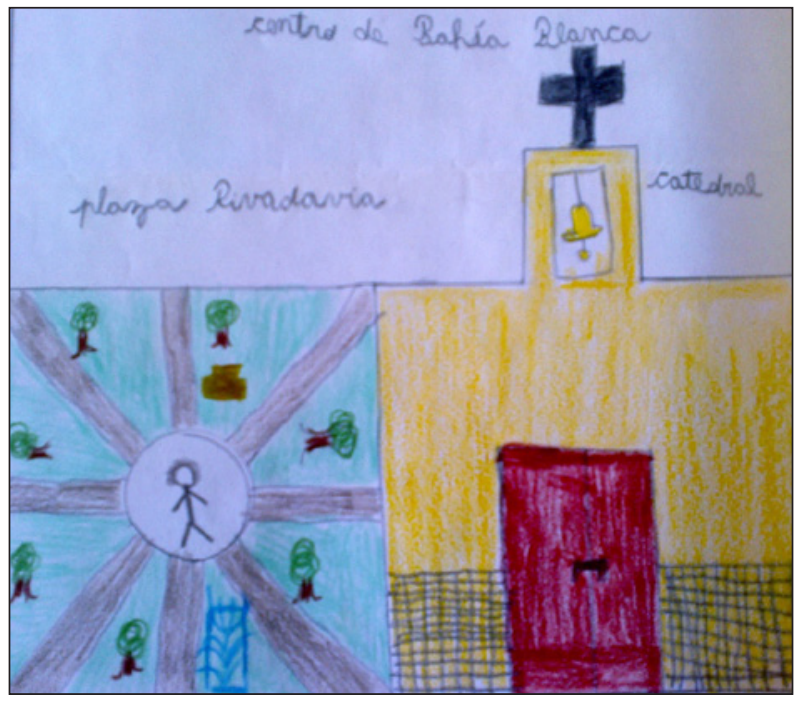

Fuente: elaborado por Morena (7 años).

Figura 14

REPRESENTACIONES DEL TEATRO MUNICIPAL

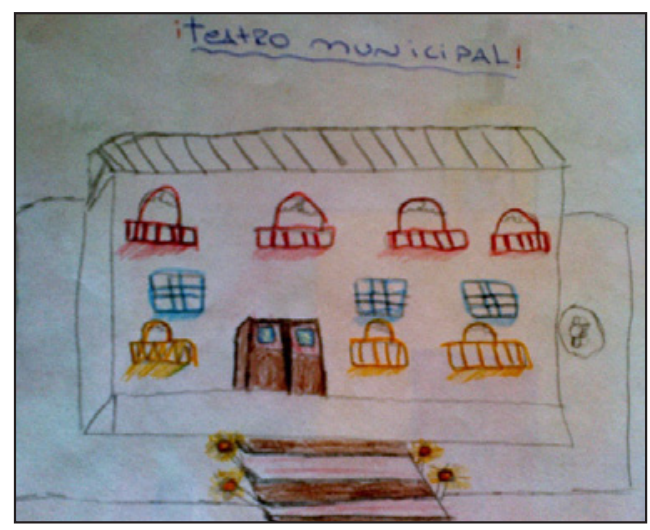

Fuente: elaborado por Gonzalo (11 años).

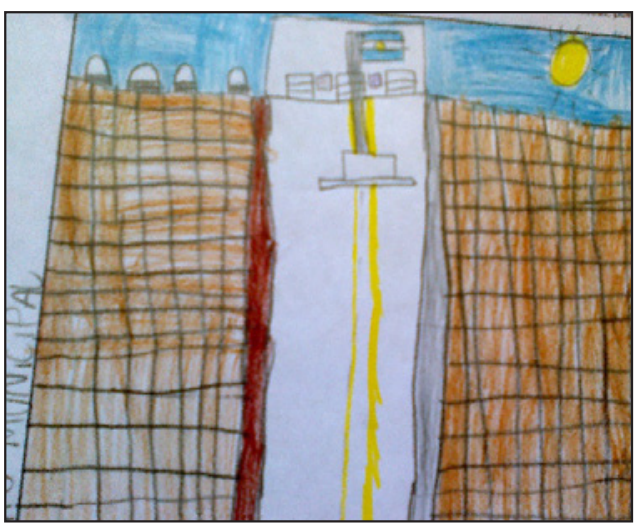

Fuente: elaborado por Blas (8 años).

dos de los niños. Es el caso del antiguo edifico del Hotel Italia (actualmente en proceso de refuncionalización), el denominado edificio de Correos y Telégrafos, el Banco de la Nación Argentina, entre otros.

En octavo lugar, con una ponderación del $8,7 \%$, se destaca el conjunto patrimonial de la Universidad Nacional del Sur, el mismo se conforma por el edificio de la institución y 
la fuente «Lola Mora», nombre que hace referencia a la escultora tucumana que realizó los capullos que forman parte de ella. Este espacio, además de constituir uno de los de mayor prestigio a escala local, es utilizado como sitio característico en las postales y fotografías de eventos (cumpleaños, casamientos, etc.), lo que le otorga una valorización social mayor.

Entre los componentes que adquieren reducida representación, inferior al 2\%, se destacan: las estaciones ferroviarias, con la Estación Sud como la más dibujada; la Biblioteca Popular Bernardino Rivadavia; las expresiones del patrimonio cultural inmaterial, con las artesanías y el mate ${ }^{10}$ como los elementos más destacados y, por último, los museos.

Si se analizan las representaciones de los espacios subjetivos de los individuos con relación a la escala representada, puede inferirse que en la escala barrial cobran relevancia los componentes patrimoniales que estructuran parte del patrimonio urbano de cada sector, mientras que en la escala ciudad el portal de ingreso al Parque de Mayo, el sector portuario, el edificio de la Municipalidad, la Universidad Nacional del Sur y el Teatro Municipal, son los que mayor peso adquieren en las imágenes mentales (Fig. 15).

Figura 15

REPRESENTACIÓN DE LOS PRINCIPALES COMPONENTES A ESCALA CIUDAD

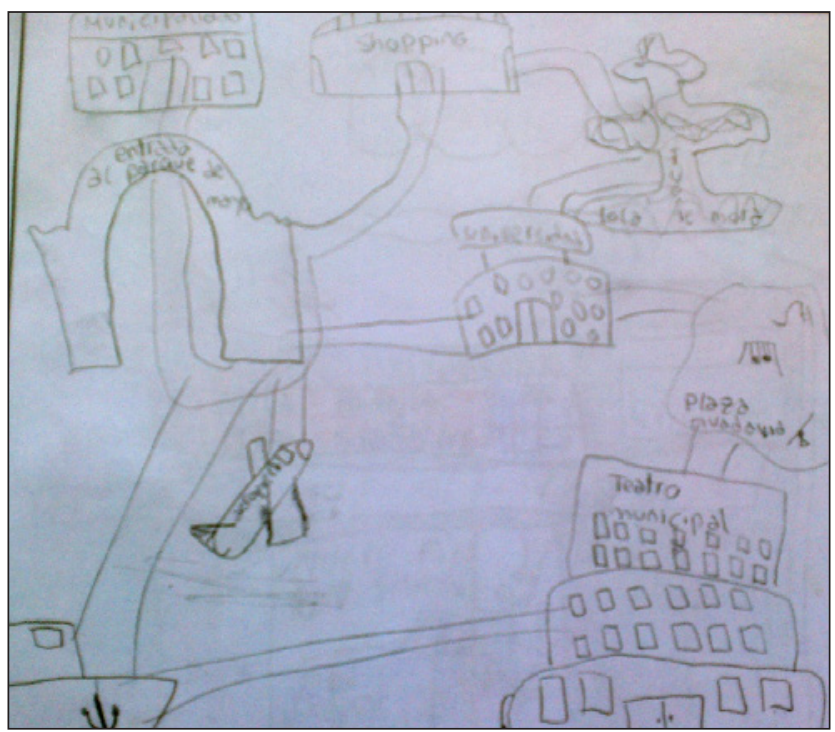

Fuente: Elaborado por Mora (11 años).

Teniendo en cuenta únicamente tres de los tipos de representación que establece Caneto (2000): cartográfica, fotográfica o esquemática, se determinó si el emplazamiento de cada uno los bienes patrimoniales resultó adecuado (en términos aproximados), según su posición relativa al resto de elementos que estructuran el mapa cognitivo. En este contexto, el $60 \%$ se localizó de forma errónea, mientras que sólo el $40 \%$ fue correcto.

10 Cabe aclarar que el mate forma parte del patrimonio gastronómico nacional, no sólo bahiense. 
Respecto a los espacios de consumo, como se mencionara, los mismos se posicionan en tercer lugar en las representaciones, luego de los espacios recreativos y patrimoniales. Los comercios del sector céntrico son los de mayor reiteración (60,9\%). En este contexto, se destaca con frecuencia, principalmente en las instituciones educativas de carácter público, el tramo de la peatonal Drago, localizado entre las calles O’Higgins y Donado. Se reflejan en ella los principales comercios que se emplazan en torno al sector de juegos infantiles. A manera de representación fotográfica, se enumeran los principales locales de uso comercial: heladerías, empresas de electrodomésticos y de celulares, comercios de ropa, jugueterías, entre otros. Asimismo, las empresas abocadas a la restauración o gastronomía, como Mc Donald y Big Six, cobran protagonismo, como también los comercios ubicados en las cuadras próximas a la Plaza Rivadavia (Fig. 16).

\section{Figura 16}

REPRESENTACIÓN DE LOS ESPACIOS DE CONSUMO EN EL ÁREA CENTRAL

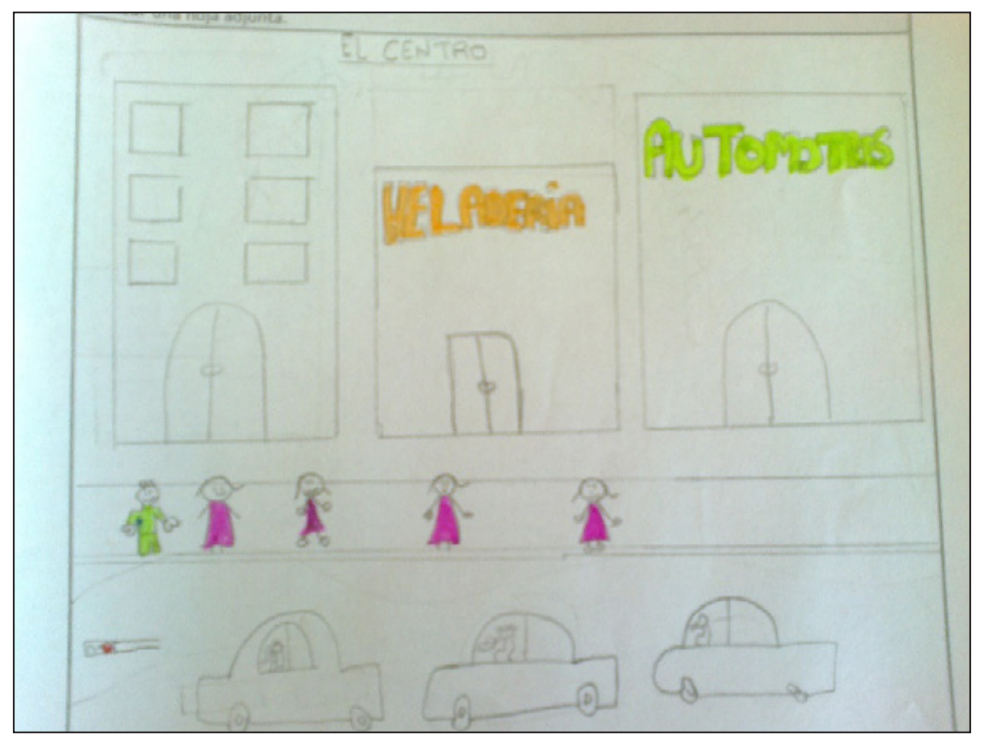

Fuente: Elaborado por Natacha (11 años).

En segunda posición se localizan otros comercios con el 24,3\%. En este caso, se consideran diversos espacios que se emplazan en el resto de la trama urbana, fuera del sector céntrico. Se incluyen aquí: comercios barriales, el complejo localizado en el extremo Este de la Avenida Cabrera (supermercados Walmart, mayorista Makro, Hipertehuelche, etc.), las distintas empresas de la Cooperativa Obrera Limitada, entre otros.

Por último, el centro comercial (Shopping) se posiciona en el tercer lugar promediando el $15 \%$ del total muestral.

Si se correlaciona estos espacios con las distintas instituciones educativas con las que se ha trabajado (Fig. 17), en la mayoría de ellas, los espacios de consumo del área central ocupan el primer lugar, igual que a nivel general. Sin embargo, en las escuelas pertenecientes 
a las delegaciones: Norte y Villa Harding Green, se observa la prevalencia de otros comercios. En el primer caso, la elección de la sede principal del Hipermercado de la Cooperativa Obrera, ha sido clave; mientras que en el segundo, la localización absoluta propia de la Delegación y, a su vez, relativa con respecto al centro de la ciudad, determina una primacía de los comercios barriales. En este último caso, debe manifestarse que el porcentaje resulta homólogo al del centro comercial (shopping). Esto puede explicarse, dada la proximidad y facilidad de acceso al mismo desde el barrio, ya que para trasladarse al centro, casi obligatoriamente deben pasar frente a él, ya sea que se desplacen en forma particular, como en el servicio de transporte público. Tal connotación puede ser una de las causales de la consideración en los mapas mentales. Por último, otro caracter a destacar es la representatividad que adquiere el Shopping en las instituciones de educación privada, pudiendo establecerse un nexo entre el nivel socioeconómico y el acceso al consumo.

Figura 17

ESPACIOS DE CONSUMO REPRESENTADOS POR INSTITUCIÓN EDUCATIVA (\%)

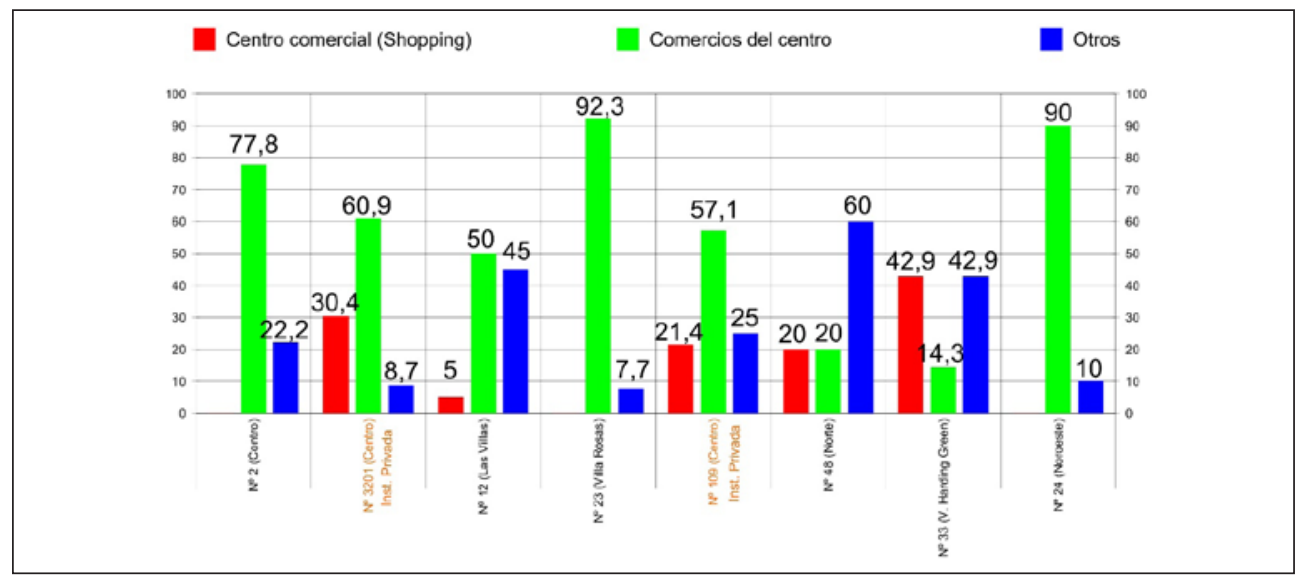

Fuente: elaboración propia (2015).

\section{REFLEXIONES FINALES}

La ciudad se configura como un territorio dinámico y complejo, estructurado sobre la base de espacios materiales, que constituyen la trama urbana: infraestructura, equipamiento y demás mobiliario; y espacios subjetivos, propios de cada individuo, que determinan cierta valorización sobre determinados componentes o lugares.

Los espacios recreativos se posicionan como medios para la socialización y el esparcimiento de la comunidad. En el caso de los niños, dichos sitios se consolidan como elementos urbanos fundamentales en el proceso de crecimiento e intercambio de valores sociales. Por otro lado, los espacios patrimoniales, funcionan como difusores de identidad cultural en un contexto urbano cambiante y atravesado por preceptos contemporáneos. Los mismos, conforman retazos de historia comunitaria, que deben ser preservados como símbolo del pasado y del devenir local. 
En el trabajo se ha analizado la valorización de dichos espacios a partir de mapas mentales de alumnos de educación primaria de la ciudad de Bahía Blanca. Como se manifestara en el procedimiento metodológico, se ha utilizado un muestreo no probabilístico o dirigido, que llevó a obtener una muestra de 825 alumnos. Realizando los cálculos con base en una población total de 28.508 residentes (INDEC, 2010) que tienen entre 6 y 11 años de edad, con un $95 \%$ de nivel de confianza y un porcentaje de error del $5 \%$, que es el más utilizado en los estudios de corte social (Hernández, Fernández y Baptista, 2006), se obtiene una muestra configurada por 649 individuos. En este contexto, el número de unidades de análisis con el que se ha trabajado, excede tales valores en un margen amplio, por lo que la representatividad de los resultados obtenidos resulta notoria a los fines de extenderla al universo en cuestión.

A partir del estudio realizado, se puede inferir que el espacio vivido de los niños de la ciudad de Bahía Blanca se estructura a partir de espacios de socialización vinculados a la recreación y el esparcimiento, en detrimento de aquellos asociados a la historia y cultura del lugar. En este sentido, puede manifestarse que los sitios contemporáneos, con base en la recreación y el consumo, prevalecen antes que aquellos vinculados al patrimonio cultural. En este caso, tal afirmación se sustenta en el peso que adquieren ambas categorías espaciales analizadas en forma conjunta.

Como aporte de la investigación, además de los resultados obtenidos útiles a la toma de decisiones en el ámbito público local, resulta necesario establecer ciertos lineamientos propositivos vinculados a la temática patrimonial, que contribuyan a realzar los atributos albergados en dichos componentes y, a su vez, posicionarlos en los espacios subjetivos de los residentes en general, y de los estudiantes de educación primaria en particular, traducido ello a posteriori en acciones de protección y salvaguarda:

- En primera instancia, resulta prioritaria la incorporación en la currícula escolar de contenidos vinculados a la historia y cultura local, asociado ello a campañas de concienciación patrimonial, que contribuyan a una mayor valorización social del patrimonio bahiense.

- Por otro lado, desde el ámbito público resulta fundamental el afianzamiento y ampliación de forma regular y extendida de un programa que propicie los paseos por aquellos atractivos turístico recreativos de carácter cultural, destinados a alumnos de educación inicial, primaria y media.

- En otra esfera, el desarrollo de actividades lúdicas o juegos infantiles de carácter educativo en espacios verdes, basados en técnicas de interpretación del patrimonio (tanto natural como cultural), favorecería la concientización de residentes a partir de herramientas que propicien el aprendizaje de forma interactiva. Algunas plazas y parques, como la Plaza Rivadavia o el Parque de Mayo, además de ser espacios de ocio de gran representatividad, se configuran como espacios patrimoniales.

- Por otro lado, se debe contribuir a la mejora e incorporación de señalética patrimonial en diferentes sitios que forman parte del patrimonio urbano. De esta manera, se comunican los valores de los recursos culturales, contribuyendo así a un mayor conocimiento y cuidado del mismo. Las TIC (Tecnologías de la Información y Comunicación) constituyen un escenario propicio para la implementación de dicha iniciativa, 
dado que posibilitan la utilización de diversas herramientas (realidad aumentada, virtual, etc.), que resultan atractivas para disímiles perfiles de usuarios, principalmente niños y adolescentes.

- En la esfera del ocio, mediante el desarrollo de espectáculos al aire libre, se podría favorecer la concreción de actividades de carácter infantil que contribuyan al conocimiento del espacio geográfico local.

- Desde el ámbito universitario, el impulso de cursos y seminarios de capacitación docente, propiciarían la formación de maestros en temáticas vinculadas a la cultura en el ámbito de la ciudad. Los Proyectos de Extensión Universitaria, pueden funcionar además como pilares complementarios de dichas iniciativas.

Los lineamientos establecidos funcionan como propuestas iniciales, que desde el ámbito educativo y de gobierno deben considerarse como ejes prioritarios en la esfera de gestión y preservación de los espacios patrimoniales. Cada uno de ellos, debe fundamentarse en un proyecto exhaustivo que describa de forma detallada las iniciativas a concretarse. En este sentido, es necesaria no sólo la programación desde los ámbitos correspondientes de planificación, sino también la implicación de la sociedad local, a partir de una participación activa, que determine y considere fines e intereses sociales de la comunidad. En este caso, los niños como principales destinatarios, deben integrarse al proceso de gestión a partir de procedimientos acordes al segmento etario con el que se esté trabajando. De esta manera, la metodología de los mapas mentales puede resultar útil, articulada con otras herramientas, que posibiliten el desarrollo de iniciativas basadas en la percepción de los propios usuarios y no en meras estrategias verticalistas impuestas por los órganos de gobierno específicos.

\section{BIBLIOGRAFÍA}

ACEBO IBÁÑEZ, E. y SCHLÜTER, R. (2012): Diccionario de turismo. Buenos Aires. Claridad.

ACERENZA, M. (1991): Administración del turismo. Conceptualización y organización. México. Trillas.

ACERENZA, M. (2006): Conceptualización, origen y evolución del turismo. México. Trillas.

ALBA, M. (2004): «El método ALCESTE y su aplicación al estudio de las representaciones sociales del espacio urbano: el caso de la ciudad de México». Papers on Social Representations, Vol. 13, 1-20.

ALBA, M. (2010): «Representaciones sociales y el estudio del territorio: aportaciones desde el campo de la Psicología Social» en La integración de la dimensión espacial en las ciencias sociales y humanidades: un proyecto docente interdisciplinario (Salomón González, Coord.). México, Ed. UAM-Cuajimalpa, 5-32.

ARIAS INCOLLA, N. (2012): «Nuestro patrimonio cultural: una construcción colectiva» en Patrimonio Argentino. Teatros, cines y auditorios (Arq. Clarín), Buenos Aires, Arte Gráfico Editorial Argentino, 11-15.

BALLART HERNÁNDEZ, J. y TRESSERRAS, J. (2007): Gestión del patrimonio cultural (3ra. Ed.). Barcelona. Ariel. 
BOIRA MAIQUES, J. (1996): «Planeamiento sin percepción, educación sin participación». Actas II Jornadas de Geografía Urbana. Universidad de Alicante, 229-240.

BOIRA MAIQUES, J. (1998): «Castro, Constancio de. La geografía en la vida cotidiana. De los mapas cognitivos al prejuicio regional». Biblio $3 w$ : revista bibliográfica de geografía y ciencias sociales, 127, 5 de diciembre de 1998. Universidad de Barcelona. Disponible en: http://www.ub.edu/geocrit/b3w-127.htm.

BOIRA MAIQUES, J. (2000): «Participar para conocer. Argumentos para la innovación en la participación ciudadana y la construcción de la ciudad». Scripta Nova, Revista Electrónica de Geografía y Ciencias Sociales, n ${ }^{\circ}$ 69, Vol. 77, 1 de agosto de 2000. Universidad de Barcelona. Disponible en: http://www.ub.edu/geocrit/sn-69-77.htm.

BOIRA MAIQUES, J. (2008): «La imagen de la ciudad en la planificación y la política urbana». Iztapalapa, nº 64-65, año 29, 233-255.

BOSCH, J. (2009): «La recreación como componente de la calidad de vida del hombre» en Reflexiones y experiencias acerca del tiempo libre, el ocio y la recreación (Bosch, J. et al.). Neuquén (Argentina), Ed. Educo, 23-35.

BOULLÓN, R. (1990): Las actividades turísticas y recreacionales. El hombre como protagonista. México. Trillas.

BRÓNDOLO, M.; CAMPOS, M.; ZINGER, S.; DEL POZO, O. y LORDA, A. (1994): Geografía de Bahía Blanca. Bahía Blanca. Ediciones Encestando.

BUZAI, G. (2011): «La construcción de mapas mentales mediante apoyo geoinformático. Desde las imágenes perceptivas hacia la modelización digital». Revista Geográfica Valparaíso, Vol. 44, 1-17.

CAMARERO IZQUIERDO, C. y GARRIDO SAMANIEGO, M. (2008): Marketing del patrimonio cultural. Madrid. Pirámides.

CANETO, C. (2000): Geografía de la percepción urbana ¿Cómo vemos la ciudad? Buenos Aires. Lugar.

CASTRO AGUIRRE, C. (1997a): «La búsqueda de datos para mapas cognitivos. Guía psicológica para Geógrafos»». Anales de Geografía de la Universidad Complutense, n ${ }^{\circ} 17$, 27-38.

CASTRO AGUIRRE, C. (1997b): La Geografía en la Vida Cotidiana: de los mapas cognitivos al prejuicio regional. Barcelona. Ediciones del Serbal.

CASTRO AGUIRRE, C. (1999): «Mapas cognitivos: qué son y cómo explorarlos» en Scripta Nova, $n^{\circ} 33,1$ de febrero de 1999. Universidad de Barcelona. Disponible en http://www. ub.edu/geocrit/sn-33.htm.

CASTRO AGUIRRE, C. (2004): Mapas mentales. Pamplona. Universidad Pública de Navarra.

CASTRO AGUIRRE, C. (2005): «Geografía de la percepción como instrumento de planeamiento urbano y ordenación territorial». Universidad Pública de Navarra, 241-253. Disponible en: http://www.biblioteca.org.ar/libros/140349.pdf.

CASTRO AGUIRRE, C. y BOSQUE SENDRA, J. (1991): «Mapas mentales de la España autonómica» en Geografías personales (Bosque Sendra, J. y Díaz Muñoz, M.), Madrid, Universidad de Alcalá de Henares, 15-52.

CONTI, A. (2010): «Nuevas categorías patrimoniales: del monumento histórico al territorio» en Textos de cátedra Maestría en Gestión del Patrimonio Arquitectónico y Urbano 
(IV) (París Benito, F. y Novacovsky, A. Comp.), Mar del Plata (Argentina), Universidad Nacional de Mar del Plata, 127-139.

CRESPí VALLBONA, M. y PLANELlS COSTA, M. (2003): Patrimonio cultural. Madrid. Síntesis.

ESCOBAR MARTÍNEZ, F. (1992): «El esquema cognitivo del espacio urbano» en Prácticas de la geografía de la percepción y de la actividad cotidiana (Bosque Sendra, J. et al.), Barcelona, Ed. Oikus-Tau, 45-101.

ESCUDERO GÓMEZ, L. (2013): «La imagen urbana de Santiago de Compostela (España), un estudio de su representación pública, mediática, promocional y artística». Boletín de la Asociación de Geógrafos Españoles, n ${ }^{\circ}$ 62, 265-294.

ESTÉBANEZ ÁLVAREZ (2000): «Problemas de interpretación y valoración de los mapas mentales» en Lecturas geográficas: homenaje a José Estébanez Álvarez, Madrid, Editorial Complutense, 149-172.

FERIA TORIBIO, J. (2010): «Patrimonio territorial y desarrollo sostenible: un estudio comparativo en Iberoamérica y España». Estudios Geográficos, n 268, Vol. LXXI, 129-159.

FERIA TORIBIO, J. (2013): «El patrimonio territorial: algunas aportaciones para su entendimiento y puesta en valor». Revista Electrónica de Patrimonio Histórico, $\mathrm{n}^{\circ}$ 12, 1-25.

FERNÁNDEZ, G. (2013): «La geografía de la percepción y la geografía humanista en la enseñanza terciaria. Algunos ejemplos». GeoUSAL: Revista Científica de Geografía, $\mathrm{n}^{\circ}$ 7, Vol. 13, 1-13.

FLORIDO TRUJILLO, G. (2013): «El patrimonio territorial en el plan de ordenación del territorio de Andalucía: indefiniciones y dificultades para un conocimiento preciso». Boletín de la Asociación de Geógrafos Españoles, nº 63, 173-201.

GARCÍA PÉREZ, F. (2002): «Concepciones de los alumnos y conocimiento escolar. Un estudio en el ámbito del medio urbano». Enseñanza de las ciencias sociales: revista de investigación, $\mathrm{n}^{\circ} 1,17-25$.

HERNÁNDEZ HERNÁNDEZ, F. (2002): El patrimonio cultural: la memoria recuperada. Asturias. Trea.

HERNÁNDEZ SAMPIERI, R.; FERNÁNDEZ-COLLADO, C. y BAPTISTA LUCIO, P. (2006): Metodología de la investigación (4ta. Ed.). México. Ed. McGraw-Hill Interamericana.

IAZZETTA DI STASIO, E. (2002): «Una metodología de planificación turística y recreacional para parques urbanos en frentes de agua». Cuadernos de Turismo, nº 10, 167-180.

ICOMOS (Consejo Internacional de Monumentos y Sitios) (1999): Carta internacional sobre turismo cultural: la gestión del turismo en los sitios con patrimonio significativo. México. ICOMOS.

LERMA RODRÍGUEZ, E. (2013): «Espacio vivido: del espacio local al reticular. Notas en torno a la representación social del espacio vivido en la globalización». Revista Pueblos y Fronteras Digital, $\mathrm{n}^{\circ}$ 15, Vol. 8, 225-250.

LINDÓN, A.; AGUILAR, M. y HIERNAUX, D. (Coords.) (2006): Lugares e imaginarios en la metrópolis. México. Anthropos.

LYNCH, K. (1959 [2008]): La imagen de la ciudad. Barcelona: Ediciones Gustavo Gili.

MEJÍA, M. y VALLADARES, P. (2011): Manual de gestión cultural para voluntarios. Tegucigalpa (Honduras). Programa de Voluntarios de las Naciones Unidas (ONU). 
MILGRAM, S. (2010): The individual in a social world: Essays and experiments (3rd expanded edition). United Kingdom. Pinter \& Martin.

MORALES HERNÁNDEZ, A.; CAURÍN ALONSO, C. y SOUTO GONZÁLEZ, X. (2013): «Percepción del mundo: mapas mentales y problemas socioambientales». Didáctica geográfica, $\mathrm{n}^{\mathrm{o}} 14,91-108$.

MOREIRA-WACHTEL, S. y TRÉLLEZ SOLÍS, E. (2013): La interpretación del patrimonio natural y cultural. Una visión intercultural y participativa. Lima. Ministerio de Ambiente del Perú.

NAVEIRO, M. (2015): «La inclusión de los mapas cognitivos en los sistemas de evaluación». Revista de geografía e ordenamento do território, $\mathrm{n}^{\circ}$ 7, Vol. 1, 251-270.

ORTEGA VALCÁRCEL, J. (1998): «Patrimonio territorial: el territorio como recursos cultural y económico». Ciudades, $\mathrm{n}^{\circ}$ 4, 33-48.

PARDO ABAD, C. (2008): Turismo y patrimonio industrial. Madrid. Síntesis.

PILLET CAPDEPÓN, F. (2004): «La geografía y las distintas acepciones del espacio geográfico». Investigaciones geográficas, $\mathrm{n}^{\circ} 34,141-154$.

PINASSI, A. (2013): «Los recreacionistas culturales y la valoración turístico recreativa de áreas patrimoniales. El caso del centro histórico de Bahía Blanca (Argentina)». Pasos, Revista de Turismo y Patrimonio Cultural, $\mathrm{n}^{\circ}$ 2, Vol. 11, 351-370.

PINASSI, A. y ERCOLANI, P. (2012): «Turismo cultural en el centro histórico de Bahía Blanca. Análisis y propuestas para su desarrollo turístico- recreativo». Anuario de Turismo y Sociedad, n 13, 145-169.

PRATS, L. (1997): Antropología y patrimonio. Barcelona. Ariel.

PRATS, L. (1998): «El concepto de patrimonio cultural». Política y Sociedad, n 27, 63-76.

PRATS, L. (2005): «Concepto y gestión del patrimonio local». Cuadernos de Antropología Social, $\mathrm{n}^{\mathrm{0}} 21,17-35$.

PRATS, L. (2006): «La mercantilización del patrimonio: entre la economía turística y las representaciones identitarias». PH, Boletín del Instituto Andaluz del Patrimonio Histórico, $\mathrm{n}^{\mathrm{o}} 58,72-80$.

PRATS, L. (2014): «El carácter magmàtic del patrimoni etnològic». Revista D'Etnologia de Catalunya, no $39,152-159$.

QUEROL, M. (2010): Manual de gestión del patrimonio cultural. Madrid. Akal.

REQUES VELASCO, P. y BOIRA MAIQUES, J. (1992): «Balance crítico de dos décadas de geografía de la percepción en España. A propósito de los estudios sobre espacios urbanos». Actas V Coloquio de Geografía Cuantitativa, Universidad de Zaragoza, 341-356.

RUBIO, L. y SANTARELLI, S. (2011): «Lugares rechazados por los adolescentes de la ciudad de Bahía Blanca». Revista Universitaria de Geografía, Vol. 20, 11-39.

SANTESMASES MESTRE, M. (2001): Dyane, Versión 2. Diseño y análisis de encuestas en investigación social y de mercados. Madrid. Pirámide.

SANTESMASES MESTRE, M. (2009): Dyane, Versión 4. Diseño y análisis de encuestas en investigación social y de mercados. Madrid. Pirámide.

SCHENKEL, E. (2013): «El derecho de las personas al turismo en Argentina. Una aproximación desde la justicia social». Revista Líder, Vol. 22, año 15, 189-206.

SOJA, E. (2008): Postmetrópolis. Estudios críticos sobre las ciudades y las regiones. Madrid. Traficantes de Sueños. 
SOUTO GONZÁLEZ, X. (1994): «Implicaciones didácticas del estudio geográfico de las ciudades». Investigaciones geográficas, nº 12, 93-118.

TONUCCI, F. (2004): «La ciudad de los niños». Cooperación educativa, $\mathrm{n}^{\circ}$ 74, 11-16.

TONUCCI, F. (2015): La ciudad de los niños. Barcelona. Grao.

TORREJÓN, A. (2013): Tesauro turístico argentino. Buenos Aires. Ministerio de Turismo de la Nación.

TRONCOSO, C. y ALMIRÓN, A. (2005): «Turismo y patrimonio. Hacia una relectura de sus relaciones». Aportes y Transferencia, nº 9, Vol. 1, 56-74.

UNESCO (Organización de las Naciones Unidas para la Educación, la Ciencia y la Cultura) (1972): Convención sobre la protección del patrimonio mundial cultural y natural. París. UNESCO.

VARA MUÑOZ, J. (2008): «Cinco décadas de Geografía de la percepción». Ería, n 77, 371-384.

VARA MUÑOZ, J. (2010): «Un análisis necesario: epistemología de la geografía de la percepción». Papeles de Geografía, nº 51-52, 337-344.

VELASCO GONZÁLEZ, M. (2009): «Gestión turística del patrimonio cultural: enfoques para un desarrollo sostenible del turismo cultural». Cuadernos de Turismo, $\mathrm{n}^{\circ}$ 23, 237 253.

VIVAS I ELIAS, P. et al. (2005): Ventanas en la ciudad. Observaciones sobre las urbes contemporáneas. Barcelona. UOC.

\section{Sitios web}

Dirección General de Cultura y Educación de la Pcia. de Bs. As. http://abc.gov.ar/. (Acceso: Febrero de 2015).

Instituto Nacional de Estadísticas y Censos (INDEC). http://www.indec.mecon.ar/ (Acceso: Diciembre de 2014).

Municipalidad de Bahía Blanca (MBB). http://www.bahiablanca.gov.ar/ (Acceso: Diciembre de 2014).

Real Academia Española (RAE). http://www.rae.es/ (Acceso: Febrero de 2015). 